\title{
Kinetic model framework for aerosol and cloud surface chemistry and gas-particle interactions - Part 2: Exemplary practical applications and numerical simulations
}

\author{
M. Ammann ${ }^{1}$ and U. Pöschl ${ }^{2, *}$ \\ ${ }^{1}$ Paul Scherrer Institute, CH-5232 Villigen PSI, Switzerland \\ ${ }^{2}$ Technical University of Munich, Institute of Hydrochemistry, Marchioninistr. 17, 81377 Munich, Germany \\ *now at: Max Planck Institute for Chemistry, Biogeochemistry Department, 55128 Mainz, Germany
}

Received: 20 January 2005 - Published in Atmos. Chem. Phys. Discuss.: 11 April 2005

Revised: 28 September 2007 - Accepted: 4 November 2007 - Published: 10 December 2007

\begin{abstract}
A kinetic model framework with consistent and unambiguous terminology and universally applicable rate equations and parameters for aerosol and cloud surface chemistry and gas-particle interactions has been presented in the preceding companion paper by Pöschl, Rudich and Ammann (Pöschl et al., 2007), abbreviated PRA. It allows to describe mass transport and chemical reaction at the gasparticle interface and to link aerosol and cloud surface processes with gas phase and particle bulk processes. Here we present multiple exemplary model systems and calculations illustrating how the general mass balance and rate equations of the PRA framework can be easily reduced to compact sets of equations which enable a mechanistic description of time and concentration dependencies of trace gas uptake and particle composition in systems with one or more chemical components and physicochemical processes.

Time-dependent model scenarios show the effects of reversible adsorption, surface-bulk transport, and chemical aging on the temporal evolution of trace gas uptake by solid particles and solubility saturation of liquid particles. They demonstrate how the transformation of particles and the variation of trace gas accommodation and uptake coefficients by orders of magnitude over time scales of microseconds to days can be explained and predicted from the initial composition and basic kinetic parameters of model systems by iterative calculations using standard spreadsheet programs. Moreover, they show how apparently inconsistent experimental data sets obtained with different techniques and on different time scales can be efficiently linked and mechanistically explained by application of consistent model formalisms and terminologies within the PRA framework.
\end{abstract}

Correspondence to: M. Ammann

(markus.ammann@psi.ch)
Steady-state model scenarios illustrate characteristic effects of gas phase composition and basic kinetic parameters on the rates of mass transport and chemical reactions. They demonstrate how adsorption and surface saturation effects can explain non-linear gas phase concentration dependencies of surface and bulk accommodation coefficients, uptake coefficients, and bulk solubilities (deviations from Henry's law). Such effects are expected to play an important role in many real atmospheric aerosol and cloud systems involving a wide range of organic and inorganic components of concentrated aqueous and organic solution droplets, ice crystals, and other crystalline or amorphous solid particles.

\section{Introduction}

Surface processes and gas-particle interactions of aerosols and clouds are important aspects of atmospheric chemistry and physics. They influence the atmospheric budget of ozone and other trace gases, the atmospheric residence time of particles and their influence on the hydrological cycle, the radiative properties of the atmosphere, and the health effects of inhaled particles. In the preceding companion paper by Pöschl, Rudich, and Ammann (Pöschl et al., 2007), further on referred to as PRA, we have presented a kinetic model framework with consistent and unambiguous terminology and universally applicable rate equations and parameters, which describes mass transport and chemical reactions at the gasparticle interface and to link aerosol and cloud surface processes with gas phase and particle bulk processes in systems with multiple chemical components and competing physicochemical processes.

Published by Copernicus Publications on behalf of the European Geosciences Union. 
As detailed in the preceding companion paper, the key elements and essential aspects of the PRA framework are: a simple and descriptive double-layer surface model (sorption layer and quasi-static layer); straightforward flux-based mass balance and rate equations; clear separation of mass transport and chemical reaction; well-defined rate parameters (uptake and accommodation coefficients, reaction probabilities, reaction rate coefficients, and mass transport rate coefficients); clear separation of gas phase, gas-surface, and surface-bulk transport (gas phase diffusion correction, surface and bulk accommodation); clear separation of gassurface, surface layer, and surface-bulk reactions (LangmuirHinshelwood and Eley-Rideal mechanisms); mechanistic description of concentration and time dependencies; flexible inclusion/omission of chemical species and physicochemical processes; flexible convolution/deconvolution of species and processes; and full compatibility with traditional resistor model formulations. The PRA framework is meant to provide a common conceptual basis for experimental and theoretical studies of atmospheric aerosol and cloud surface chemistry and gas-particle interactions. Its practical applicability and flexibility shall be illustrated in this paper.

One of the primary aims of the flux-based PRA mass balance and rate equations is the efficient mechanistic description of concentration and time dependencies of reactive and non-reactive gas uptake and particle surface aging. In Sect. 2 of this manuscript we show how the temporal evolution of surface composition, accommodation and uptake coefficients can be efficiently followed over timescales from microseconds to days. Exemplary numerical simulations will be presented for model systems referring to earlier studies and literature data of trace gas uptake onto solids (Sect. 2.1) and into liquids (Sect. 2.2). In Sect. 3 we illustrate characteristic effects of gas phase composition and basic rate coefficients on surface coverages, surface and bulk accommodation coefficients, uptake coefficients, and bulk solubilities of trace gases interacting with solid and liquid particles under (quasi-)steady-state conditions. Throughout this manuscript we will use the terminology of the PRA framework. For definitions and a list of symbols see the preceding companion paper (Pöschl et al., 2007). Overall, the exemplary calculations presented here concentrate on the quantities that determine rates of disappearance from the gas phase or equilibration with the gas phase, but not so much on the temporal evolution of surface and bulk composition. These can be obtained in a straightforward way using the PRA framework. Further examples related to aerosol processing will be presented in forthcoming papers.

\section{Time dependencies of gas uptake and particle compo- sition}

The PRA flux formalism, mass balance and rate equations enable efficient description of mass transport, chemical re- actions, and surface composition in time-dependent aerosol and cloud systems with multiple chemical species and competing processes. For such systems, the surface mass balance equations given in PRA Sect. 3.1 lead to a set of coupled differential equations, which can be solved numerically by inserting the rate equations given in PRA Sects. 3.2-3.6 or alternative/complementary mathematical descriptions of the involved physicochemical processes. Required input parameters are the initial concentrations of relevant chemical species and the corresponding mass transport and reaction rate coefficients.

Here we consider a few simple model systems and scenarios of gas uptake onto solid and into liquid particles. The simulations were performed by iterative integration of the equations specified below with a standard spreadsheet program (Microsoft Excel 2000). The selected examples have been chosen to show how reversible adsorption (accommodation and competition for surface area in the sorption layer) and chemical aging (transformation of the quasi-static layer) can influence the time dependence of surface and bulk accommodation coefficients and uptake coefficients. Some of the input parameters for the numerical simulations have been adopted from experimental studies. The primary aim of the model systems and scenarios presented in this paper, however, is not to describe specific systems but to illustrate the flexibility of the PRA framework and its suitability to describe generic features of gas-particle interaction kinetics.

\subsection{Reactive gas uptake and transformation of solid particle surfaces}

\subsubsection{Model system Solid 1 (S1): adsorption and sequential} surface layer reactions with particle components

In this model system we consider a trace gas $X_{1}$, which undergoes reversible adsorption and irreversible surface layer reactions on the surface of a solid particle, which initially consists of the non-volatile component $Y_{1}$. In a sequence of three surface layer reactions, $\mathrm{Y}_{1}$ can be converted into the chemical derivatives $\mathrm{Y}_{2}, \mathrm{Y}_{3}$, and $\mathrm{Y}_{4}$, respectively: SLR1: $\mathrm{X}_{1}(\mathrm{~s})+\mathrm{Y}_{1}(\mathrm{ss}) \rightarrow \mathrm{Y}_{2}(\mathrm{ss}) ; \quad$ SLR2: $\quad \mathrm{X}_{1}(\mathrm{~s})+\mathrm{Y}_{2}(\mathrm{ss}) \rightarrow \mathrm{Y}_{3}(\mathrm{ss})$; SLR3: $\quad \mathrm{X}_{1}(\mathrm{~s})+\mathrm{Y}_{3}(\mathrm{ss}) \rightarrow \mathrm{Y}_{4}(\mathrm{ss})$. $\quad$ Surface-bulk transport processes as well as elementary gas-surface and surface bulk-reactions are assumed to be negligible. Under these conditions, the general PRA surface mass balance and rate equations can be reduced to:

$$
\begin{aligned}
& \mathrm{d}\left[\mathrm{X}_{1}\right]_{\mathrm{s}} / \mathrm{d} t=J_{\mathrm{ads}, \mathrm{X} 1}-J_{\mathrm{des}, \mathrm{X} 1}-L_{\mathrm{s}, \mathrm{X} 1} \\
& \mathrm{~d}\left[\mathrm{Y}_{1}\right]_{\mathrm{ss}} / \mathrm{d} t=-L_{\mathrm{ss}, \mathrm{Y} 1} \\
& \mathrm{~d}\left[\mathrm{Y}_{2}\right]_{\mathrm{ss}} / \mathrm{d} t=P_{\mathrm{ss}, \mathrm{Y} 2}-L_{\mathrm{ss}, \mathrm{Y} 2} \\
& \mathrm{~d}\left[\mathrm{Y}_{3}\right]_{\mathrm{ss}} / \mathrm{d} t=P_{\mathrm{ss}, \mathrm{Y} 3}-L_{\mathrm{ss}, \mathrm{Y} 3} \\
& \mathrm{~d}\left[\mathrm{Y}_{4}\right]_{\mathrm{ss}} / \mathrm{d} t=P_{\mathrm{ss}, \mathrm{Y} 4}
\end{aligned}
$$




$$
\begin{aligned}
& L_{\mathrm{s}, \mathrm{X} 1}=k_{\mathrm{SLR} 1, \mathrm{X} 1, \mathrm{Y} 1}\left[\mathrm{X}_{1}\right]_{\mathrm{S}}\left[\mathrm{Y}_{1}\right]_{\mathrm{ss}}
\end{aligned}
$$

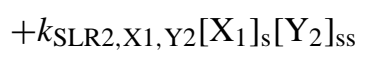

$$
\begin{aligned}
& +k_{\mathrm{SLR} 3, \mathrm{X} 1, \mathrm{Y} 3}\left[\mathrm{X}_{1}\right]_{\mathrm{s}}\left[\mathrm{Y}_{3}\right]_{\mathrm{ss}} \\
& L_{\mathrm{ss}, \mathrm{Y} 1}=k_{\mathrm{SLR} 1, \mathrm{X} 1, \mathrm{Y} 1}\left[\mathrm{X}_{1}\right]_{\mathrm{s}}\left[\mathrm{Y}_{1}\right]_{\mathrm{ss}} \\
& P_{\mathrm{Ss}, \mathrm{Y} 2}-L_{\mathrm{ss}, \mathrm{Y} 2}=k_{\mathrm{SLR} 1, \mathrm{X} 1, \mathrm{Y} 1}\left[\mathrm{X}_{1}\right]_{\mathrm{s}}\left[\mathrm{Y}_{1}\right]_{\mathrm{ss}} \\
& -k_{\mathrm{SLR} 2, \mathrm{X} 1, \mathrm{Y} 2}\left[\mathrm{X}_{1}\right]_{\mathrm{s}}\left[\mathrm{Y}_{2}\right]_{\mathrm{ss}} \\
& P_{\mathrm{ss}, \mathrm{Y} 3}-L_{\mathrm{ss}, \mathrm{Y} 3}=k_{\mathrm{SLR} 2, \mathrm{X} 1, \mathrm{Y} 2}\left[\mathrm{X}_{1}\right]_{\mathrm{s}}\left[\mathrm{Y}_{2}\right]_{\mathrm{ss}} \\
& -k_{\mathrm{SLR} 3, \mathrm{X} 1, \mathrm{Y} 3}\left[\mathrm{X}_{1}\right]_{\mathrm{S}}\left[\mathrm{Y}_{3}\right]_{\mathrm{ss}} \\
& P_{\mathrm{ss}, \mathrm{Y} 4}=k_{\mathrm{SLR} 3, \mathrm{X} 1, \mathrm{Y} 3}\left[\mathrm{X}_{1}\right]_{\mathrm{s}}\left[\mathrm{Y}_{3}\right]_{\mathrm{ss}} \\
& J_{\mathrm{ads}, \mathrm{X} 1}=\alpha_{\mathrm{s}, 0, \mathrm{X} 1} \omega_{\mathrm{X} 1} / 4\left[\mathrm{X}_{1}\right]_{\mathrm{gs}}\left(1-\theta_{\mathrm{s}}\right) \\
& \alpha_{\mathrm{s}, \mathrm{X} 1}=\alpha_{\mathrm{s}, 0, \mathrm{X} 1}\left(1-\theta_{\mathrm{s}}\right) \\
& \theta_{\mathrm{s}}=\left[\mathrm{X}_{1}\right]_{\mathrm{s}} /\left[\mathrm{X}_{1}\right]_{\mathrm{s}, \max }=\sigma_{\mathrm{s}, \mathrm{X} 1}\left[\mathrm{X}_{1}\right]_{\mathrm{s}} \\
& J_{\mathrm{des}, \mathrm{X} 1}=\tau_{\mathrm{d}, \mathrm{X} 1}^{-1}\left[\mathrm{X}_{1}\right]_{\mathrm{s}} \\
& \gamma_{\mathrm{X} 1}=\gamma_{\mathrm{sor}, \mathrm{X} 1}=\frac{J_{\mathrm{ads}, \mathrm{X} 1}-J_{\mathrm{des}, \mathrm{X} 1}}{J_{\mathrm{coll}, \mathrm{X} 1}}
\end{aligned}
$$

The model system and rate equations outlined above correspond to a Langmuir-Hinshelwood-type mechanism as discussed by Ammann et al. (2003). Note, however, that the classical Langmuir-Hinshelwood mechanisms and rate equations known from the chemical engineering literature usually refer to reactions between two adsorbed species (heterogeneous catalysis) rather than one adsorbed species and one quasi-static surface layer component.

For the exemplary model simulations illustrated in Fig. 1, the following input parameters have been used in the iterative calculation and integration of Eqs. (1)-(11): $\alpha_{\mathrm{s}, 0, \mathrm{X} 1}=10^{-3}$; $\omega_{\mathrm{X} 1}=3.6 \times 10^{4} \mathrm{~cm} \mathrm{~s}^{-1} ; \tau_{\mathrm{d}, \mathrm{X} 1}=18 \mathrm{~s} ; \sigma_{\mathrm{X} 1}=1.8 \times 10^{-15} \mathrm{~cm}^{2}$, $k_{\mathrm{SLR} 1, \mathrm{X} 1, \mathrm{Y} 1}=2.1 \times 10^{-17} \mathrm{~cm}^{2} \mathrm{~s}^{-1}, k_{\mathrm{SLR} 2, \mathrm{X} 1, \mathrm{Y} 2}=2.1 \times$ $10^{-19} \mathrm{~cm}^{2} \mathrm{~s}^{-1}, \quad k_{\mathrm{SLR} 3, \mathrm{X} 1, \mathrm{Y} 3}=2.1 \times 10^{-21} \mathrm{~cm}^{2} \mathrm{~s}^{-1}$, $\left[\mathrm{Y}_{1}\right]_{\mathrm{ss}, \mathrm{ini}}=1 \times 10^{14} \mathrm{~cm}^{-2},\left[\mathrm{X}_{1}\right]_{\mathrm{gs}}=2.5 \times 10^{13} \mathrm{~cm}^{-3}$ (scenario $\mathrm{S} 1-1)$ or $2.5 \times 10^{11} \mathrm{~cm}^{-3}$ (scenario S1-2). $\omega_{\mathrm{X} 1}, \alpha_{\mathrm{s}, 0, \mathrm{X} 1}$, $\tau_{\mathrm{X} 1}, \sigma_{\mathrm{X} 1}$, and $k_{\mathrm{SLR} 1, \mathrm{X} 1, \mathrm{Y} 1}$ are based on the values reported by Pöschl et al. (2001) for the interaction of ozone with the polycyclic aromatic hydrocarbon benzo[a]pyrene (BaP) on soot at ambient temperature and pressure. The experimental results of Pöschl et al. (2001) also support the assumption that the basic adsorption, desorption, and reaction rate parameters are not significantly affected by the chemical transformation of the quasi-static surface layer (nearidentical observations on soot particles which were fully or only partially covered with benzo[a]pyrene). Note, however, that ozone may be adsorbed either in the form of $\mathrm{O}_{3}$ molecules or in the form of $\mathrm{O}$ atoms (Pöschl et al., 2001). In the latter case the actual surface accommodation coefficient might be significantly higher than the observed shortterm uptake coefficients, which would convolute the actual
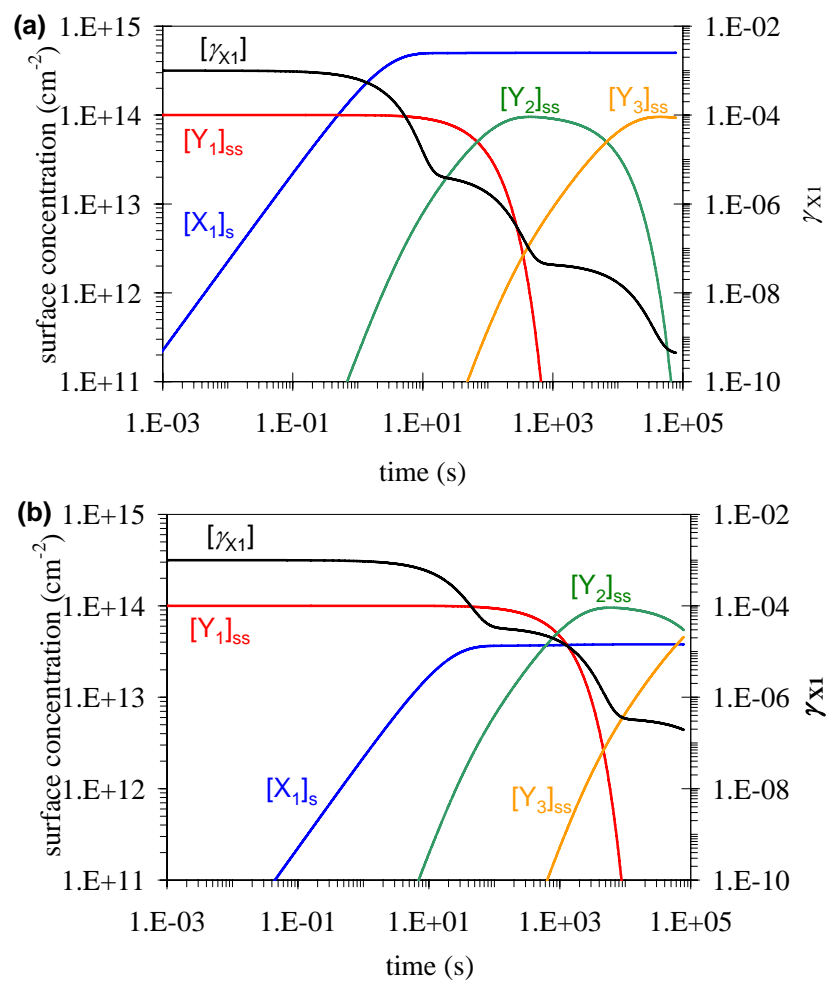

Fig. 1. Temporal evolution of the surface concentration of the volatile species in the sorption layer $\left[\mathrm{X}_{1}\right]_{\mathrm{S}}$ (blue), of the non-volatile species in the quasi-static surface layer $\left[\mathrm{Y}_{1}\right]_{\mathrm{ss}}(\mathrm{red}),\left[\mathrm{Y}_{2}\right]_{\mathrm{ss}}$ (green), $\left[\mathrm{Y}_{3}\right]_{\mathrm{ss}}$ (orange), and of the gas uptake coefficient $\gamma_{\mathrm{X} 1}$ (black) in model system $\mathrm{S} 1$ (adsorption and sequential surface layer reactions): scenario S1-1 with $\left[\mathrm{X}_{1}\right]_{\mathrm{gs}}=2.5 \times 10^{13} \mathrm{~cm}^{-3}$ (a) and scenario S1-2 with $\left[X_{1}\right]_{\mathrm{gs}}=2.5 \times 10^{11} \mathrm{~cm}^{-3}(\mathbf{b})$.

accommodation process and a surface reaction (decomposition of $\mathrm{O}_{3}$ into $\mathrm{O}$ and $\mathrm{O}_{2}$ ). A detailed analysis and investigation of this aspect is beyond the scope of this paper, but we are planning to pursue this aspect in future studies applying the PRA framework. The reaction products $\mathrm{Y}_{2}-\mathrm{Y}_{4}$ can be pictured as $\mathrm{BaP}$ derivatives with increasing number of oxygenated functional groups and decreasing reactivity towards photooxidants (BaP-quinones, hydroxy-ketones, acid anhydrides, lactones, etc.; Letzel et al., 1999a, b, 2001; Pöschl, 2002).

In the numerical simulations, the gas phase concentration of $\mathrm{X}_{1}$ close to the surface, $\left[\mathrm{X}_{1}\right]_{\mathrm{gs}}$, was kept constant, i.e. it was assumed not to be depleted by the net uptake into the condensed phase. Due to the relatively low uptake coefficients $\left(\gamma_{\times 1} \leq 10^{-3}\right)$ this assumption is very well justified for fine soot particles (particle diameters on the order of $d_{\mathrm{p}} \approx 100 \mathrm{~nm}$ ) interacting with ozone and similar low-molecular-mass photo-oxidants like $\mathrm{OH}$, $\mathrm{NO}_{2}$, etc. (gas phase diffusion coefficients on the order of $\left.D_{\mathrm{g}, \mathrm{X} 1} \approx 0.1 \mathrm{~cm}^{2} \mathrm{~s}^{-1}\right)$. In case of significant gas phase 
depletion, the influence of gas phase diffusion could be described by the PRA gas phase correction factor $C_{\mathrm{g}, \mathrm{X} 1}$ (PRA Sect. 2). $C_{\mathrm{g}, \mathrm{X} 1}$ can be used in this as well as in all other model systems outlined below to account for gas phase diffusion effects and to relate $\left[\mathrm{X}_{1}\right]_{\mathrm{gs}}$ to the average gas phase concentration of $\mathrm{X}_{1},\left[\mathrm{X}_{1}\right]_{\mathrm{g}}$.

Figure 1a shows the surface concentrations of all involved chemical species and the uptake coefficient $\gamma_{\mathrm{X} 1}$ as a function of time from one $\mathrm{ms}$ up to one day for scenario S1-1 $\left(\left[\mathrm{X}_{1}\right]_{\mathrm{gs}}=2.5 \times 10^{13} \mathrm{~cm}^{-3}\right)$. The initial plateau of $\gamma_{\mathrm{X} 1} \approx \alpha_{\mathrm{s}, 0, \mathrm{X} 1}=10^{-3}$ up to $\sim 1 \mathrm{~s}$ is determined by adsorption onto an essentially adsorbate free surface $\left(\theta_{\mathrm{s}} \approx 0\right)$. The steep decrease of $\gamma_{\mathrm{X} 1}$ at $\sim 5 \mathrm{~s}$ is due to surface saturation with $\mathrm{X}_{1}$ (approach of quasi-steady-state surface concentration $\left[\mathrm{X}_{1}\right]_{\mathrm{s}} \approx 5 \times 10^{14} \mathrm{~cm}^{-2}$ ), and the subsequent plateau at $\sim 20 \mathrm{~s}$ and $\gamma_{\mathrm{X} 1} \approx 4 \times 10^{-6}$ is due to chemical reaction of $\mathrm{X}_{1}$ with the quasi-static layer consisting almost exclusively of $\mathrm{Y}_{1}\left(\mathrm{SLR} 1,\left[\mathrm{Y}_{1}\right]_{\mathrm{ss}, \text { ini }} \approx\left[\mathrm{Y}_{1}\right]_{\mathrm{ss}, \text { ini }}=1 \times 10^{14} \mathrm{~cm}^{-2}\right)$. The second steep decrease of $\gamma_{\mathrm{X} 1}$ at $\sim 200 \mathrm{~s}$ is due to the depletion of $\mathrm{Y}_{1}$, and the subsequent plateau at $\sim 1000 \mathrm{~s}$ and $\gamma_{X_{1}} \approx 4 \times 10^{-8}$ is due to chemical reaction of $\mathrm{X}_{1}$ with the quasi-static layer consisting almost exclusively of $\mathrm{Y}_{2}\left(\mathrm{SLR} 2,\left[\mathrm{Y}_{2}\right]_{\mathrm{ss}} \approx\left[\mathrm{Y}_{1}\right]_{\mathrm{ss}, \text { ini }}=1 \times 10^{14} \mathrm{~cm}^{-2}\right)$. The third steep decrease of $\gamma_{X_{1}}$ at $\sim 30000 \mathrm{~s}$ is due to the depletion of $\mathrm{Y}_{2}$, and the subsequent plateau at $\sim 100000 \mathrm{~s}$ and $\gamma_{\mathrm{X} 1} \approx 4 \times 10^{-10}$ is due to chemical reaction of $\mathrm{X}_{1}$ with the quasi-static layer consisting almost exclusively of $\mathrm{Y}_{3}$ (SLR3, $\left[\mathrm{Y}_{3}\right]_{\mathrm{ss}} \approx\left[\mathrm{Y}_{1}\right]_{\mathrm{ss}, \mathrm{ini}}=1 \times 10^{14} \mathrm{~cm}^{-2}$ ).

Figure $1 \mathrm{~b}$ shows the surface concentrations of all involved chemical species and the uptake coefficient $\gamma_{\mathrm{X} 1}$ as a function of time from one ms up to one day for scenario S1-2 $\left(\left[\mathrm{X}_{1}\right]_{\mathrm{gs}}=2.5 \times 10^{11} \mathrm{~cm}^{-3}\right)$. The temporal evolution is analogous to Fig. 1a (scenario S1-1), but the substantially lower gas phase concentration of $\mathrm{X}_{1}$ has the following consequences: (a) the plateaus of $\gamma_{\mathrm{X} 1}$ are more extended and the decreases are less steep (slower surface saturation and reactant depletion, respectively); (b) the plateau values of $\gamma_{\mathrm{X} 1}$ corresponding to the different surface layer reactions are higher because the decrease of $\mathrm{X}_{1}$ gas phase concentration and gas kinetic flux to the surface is much more pronounced than the corresponding decrease of $X_{1}$ surface concentration and surface layer reaction rate (Langmuir adsorption effect). Similar non-linear gas phase concentration dependencies and effects of reversible adsorption followed by surface layer reactions (Langmuir-Hinshelwood reaction mechanisms) have already been outlined by Ammann et al. (2003) and will be further discussed in Sect. 3. They are particularly important when the gas phase and surface concentrations of volatile species are high, i.e. when the (quasi-)steady-state surface coverage by adsorbate molecules is close to saturation (monolayer coverage).

Overall, Fig. 1a and b illustrates that the processes of adsorption and chemical reaction can transform the surface composition of solid particles (saturation of sorption layer and chemical aging of quasi-static surface layer), change the gas uptake coefficient over several orders of magnitude, and exhibit non-linear gas phase concentration dependencies. They clearly demonstrate that the PRA framework formalism can be used to efficiently describe these processes and effects over time scales from milliseconds to days. The time scales considered here are also covered by laboratory experiments ranging from seconds in flow reactors to days in large atmospheric simulation chambers.

2.1.2 Model system Solid 2 (S2): adsorption and parallel surface layer reactions with particle components

Again we consider a trace gas $\mathrm{X}_{1}$, which undergoes reversible adsorption and irreversible surface layer reactions on the surface of a solid particle, which initially consists of two non-volatile components $\mathrm{Y}_{1}$ and $\mathrm{Y}_{2}$. In this case $\mathrm{X}_{1}$ can react in two parallel surface layer reactions, one of them converting $\mathrm{Y}_{1}$ into a volatile product, which desorbs immediately and does not interfere with the surface any further, while the other converts $\mathrm{Y}_{1}$ into the chemical derivative $\mathrm{Y}_{2}$ : SLR1: $\mathrm{X}_{1}(\mathrm{~s})+\mathrm{Y}_{1}(\mathrm{ss}) \rightarrow$ non-interfering products; SLR2: $\mathrm{X}_{1}(\mathrm{~s})+\mathrm{Y}_{2}(\mathrm{ss}) \rightarrow \mathrm{Y}_{2}(\mathrm{ss})$. Surface-bulk transport processes as well as elementary gas-surface and surface bulk-reactions are again assumed to be negligible (Langmuir-Hinshelwoodtype mechanism). Under these conditions, the general PRA surface mass balance and rate equations for $\mathrm{X}_{1}$ and $\mathrm{Y}_{1}$ are the same as above (model system S1), except for Eq. (6), which has to be replaced by:

$$
\begin{aligned}
L_{\mathrm{ss}, \mathrm{X} 1} & =k_{\mathrm{SLR} 1, \mathrm{X} 1, \mathrm{Y} 1}\left[\mathrm{X}_{1}\right]_{\mathrm{s}}\left[\mathrm{Y}_{1}\right]_{\mathrm{ss}} \\
& +k_{\mathrm{SLR} 2, \mathrm{X} 1, \mathrm{Y} 2}\left[\mathrm{X}_{1}\right]_{\mathrm{s}}\left[\mathrm{Y}_{2}\right]_{\mathrm{ss}}
\end{aligned}
$$

For the exemplary model simulations illustrated in Fig. 2a, the following input parameters have been used in the iterative integration: $\omega_{\mathrm{X} 1}=3.6 \times 10^{4} \mathrm{~cm} \mathrm{~s}^{-1} ; \alpha_{\mathrm{s}, 0, \mathrm{X} 1}=0.14 ; \tau_{\mathrm{d}, \mathrm{X} 1}=18 \mathrm{~s}$; $\sigma_{\mathrm{X} 1}=3 \times 10^{-15} \quad \mathrm{~cm}^{2}, \quad k_{\mathrm{SLR} 1, \mathrm{X} 1, \mathrm{Y} 1=7 \times 10^{-18}} \mathrm{~cm}^{2} \quad \mathrm{~s}^{-1}$, $k_{\mathrm{SLR} 2, \mathrm{X} 1, \mathrm{Y} 2}=8 \times 10^{-19} \mathrm{~cm}^{2} \mathrm{~s}^{-1},\left[\mathrm{Y}_{1}\right]_{\mathrm{ss}, \mathrm{ini}}=5 \times 10^{14} \mathrm{~cm}^{-2}$, $\left[\mathrm{Y}_{2}\right]_{\mathrm{ss}, \mathrm{ini}}=1 \times 10^{14} \mathrm{~cm}^{-2},\left[\mathrm{X}_{1}\right]_{\mathrm{gs}}=3 \times 10^{11} \mathrm{~cm}^{-3}$ (scenario $\mathrm{S} 2-1$ ) or $1 \times 10^{12} \mathrm{~cm}^{-3}$ (scenario S2-2). $\omega_{\mathrm{X} 1}, \alpha_{\mathrm{s}, 0, \mathrm{X} 1}, \tau_{\mathrm{X} 1}$, and $\sigma_{\mathrm{X} 1}$ are based on experimental data for the adsorption and reaction of nitrogen dioxide $\left(\mathrm{NO}_{2}\right)$ at the surface of soot particles on time scales of seconds to minutes in Knudsen cell experiments (Gerecke et al., 1998), an aerosol flow reactor experiment (Ammann et al., 1998), and experiments, in which particles were deposited on filters for exposure to $\mathrm{NO}_{2}$ (Ammann et al., 1997). [Y $\left.\mathrm{Y}_{1}\right]_{\mathrm{ss}, \text { ini }}$ and $\left[\mathrm{Y}_{2}\right]_{\mathrm{ss}, \text { ini }}$ have been constrained by the total yield of products observed in these experiments. $\alpha_{\mathrm{s}, 0, \mathrm{X} 1}$ has been assumed to correspond to the low concentration limit of the initial uptake coefficient observed in the Knudsen cell experiments reported by Gerecke et al. (1998). $k_{\mathrm{SLR} 1, \mathrm{X} 1, \mathrm{Y} 1}$ and $k_{\mathrm{SLR} 2, \mathrm{X} 1, \mathrm{Y} 2}$ have been adjusted to fit the experimental data from flow tube and filter exposure studies. The features of the temporal behaviour of the uptake coefficient are very similar to the example shown in Fig. 1. In this case, the slower, parallel surface layer reaction SLR2 weakens the decreasing slope 
at longer reaction times, becoming the dominant uptake pathway, once $\mathrm{Y}_{1}$ is consumed.

Three more simulations are shown in Fig. $2 \mathrm{~b}$, in which $\alpha_{\mathrm{s}, 0, \mathrm{X} 1}=0.01 ; \quad \tau_{\mathrm{d}, \mathrm{X} 1}=0.1 \quad \mathrm{~s}$; $\sigma_{\mathrm{X} 1}=3 \times 10^{-15} \mathrm{~cm}^{2}, \quad k_{\mathrm{SLR} 1, \mathrm{X} 1, \mathrm{Y} 1=3.5 \times 10^{-16}} \mathrm{~cm}^{2} \quad \mathrm{~s}^{-1}$, $k_{\mathrm{SLR} 2, \mathrm{X} 1, \mathrm{Y} 2}=1 \times 10^{-17} \mathrm{~cm}^{2} \mathrm{~s}^{-1},\left[\mathrm{Y}_{1}\right]_{\mathrm{ss}, \mathrm{ini}}=1.2 \times 10^{13} \mathrm{~cm}^{-2}$, $\left[\mathrm{Y}_{2}\right]_{\mathrm{ss}, \text { ini }}=2.4 \times 10^{14} \mathrm{~cm}^{-2}, \quad\left[\mathrm{X}_{1}\right]_{\mathrm{gs}}=1 \times 10^{11} \mathrm{~cm}^{-3} \quad$ (scenario S2-3), $\left[\mathrm{X}_{1}\right]_{\mathrm{gs}}=3 \times 10^{11} \mathrm{~cm}^{-3} \quad$ (scenario S2-4) or $1 \times 10^{12} \mathrm{~cm}^{-3}$ (scenario S2-5). These parameters are based on experimental data for the adsorption and reaction of nitrogen dioxide $\left(\mathrm{NO}_{2}\right)$ on diesel soot deposited on filters for exposure to $\mathrm{NO}_{2}$ (Arens et al., 2002). In this case, a lower concentration of reactants was observed on the surface of this soot type, while the kinetics of the surface reaction was significantly faster than in the other scenarios S2-1 and S2-2. The general features are similar to those in Fig. 2a, the long-term reactivity being even more dominated by the reaction with $\mathrm{Y}_{2}$ in the scenarios $\mathrm{S} 2-3$ to $\mathrm{S} 2-5$.

Many more laboratory studies on the subject of the $\mathrm{NO}_{2}-$ soot reaction are available (Aubin et al., 2007, and references therein), and we are not attempting to discuss all physicochemical aspects of the methodologies and of the chemical reaction itself in detail, but rather to show the applicability of the PRA framework and the importance of considering longenough time scales. The simulations demonstrate that the assumption of suitable microphysical and chemical mechanisms and rate parameters reconciles short-term and longterm experimental results, which often appear to be inconsistent at first sight. Moreover, they demonstrate the complexity introduced into the system by just assuming two different reactants on the surface. It becomes strikingly obvious that extensive parameter variations are necessary to reliably constrain all relevant parameters.

2.1.3 Model system Solid 3 (S3): adsorption and parallel surface layer reactions including adsorbate selfreaction

In model system $\mathrm{S} 3$ a trace gas $\mathrm{X}_{1}$ undergoes reversible adsorption and irreversible surface layer reactions on the surface of a solid particle, which initially consists of the non-volatile component $Y_{1}$. In this case $X_{1}$ can react in two parallel surface layer reactions, one of them converting $\mathrm{Y}_{1}$ into the chemical derivative $\mathrm{Y}_{2}$, whereas the other one is a self-reaction of $\mathrm{X}_{1}$ leading to its decomposition into products which desorb immediately and do not interfere with the surface any further (e.g. bath gas molecules): SLR1: $\mathrm{X}_{1}(\mathrm{~s})+\mathrm{Y}_{1}(\mathrm{ss}) \rightarrow \mathrm{Y}_{2}(\mathrm{ss})$; SLR2: $\mathrm{X}_{1}(\mathrm{~s})+\mathrm{X}_{1}(\mathrm{~s}) \rightarrow$ noninterfering products. Surface-bulk transport processes as well as elementary gas-surface and surface bulk-reactions are again assumed to be negligible (Langmuir-Hinshelwoodtype mechanism). Under these conditions, the general PRA surface mass balance and rate equations for $\mathrm{X}_{1}$ and $\mathrm{Y}_{1}$ are the same as above (model system S1), except for Eq. (3) which
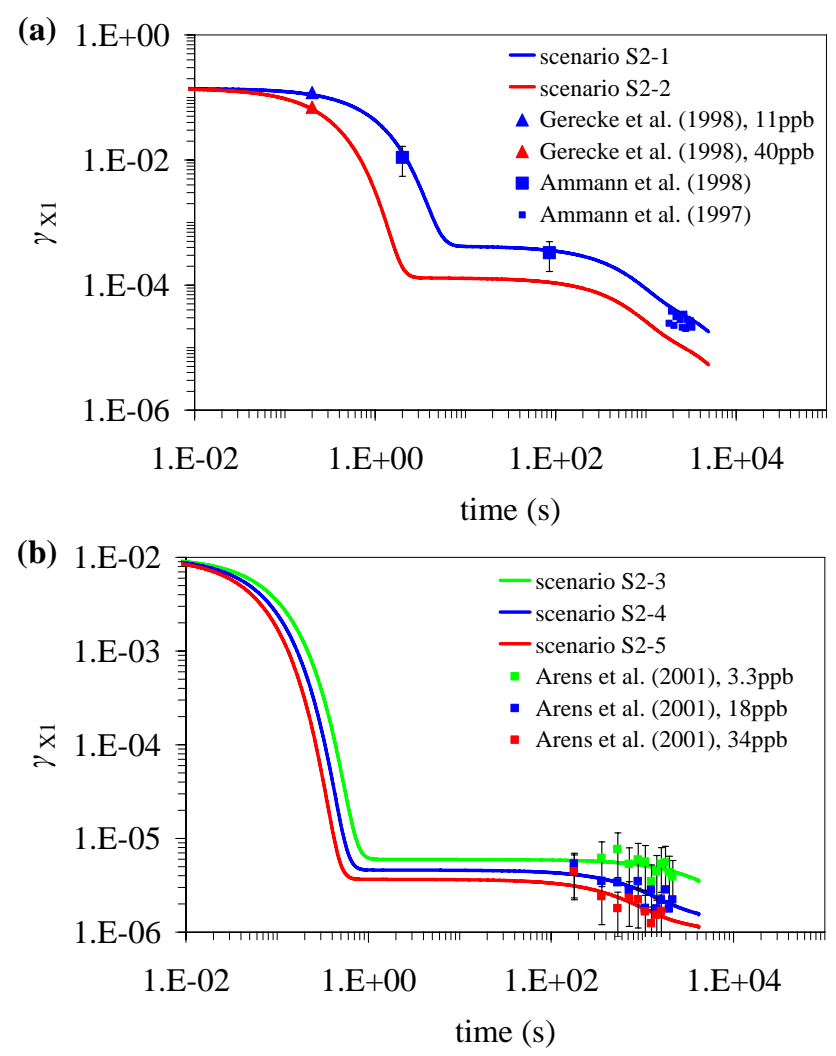

Fig. 2. Temporal evolution of the gas uptake coefficient in model system S2 (adsorption and parallel surface layer reactions): (a) scenarios $\mathrm{S} 2-1$ and $\mathrm{S} 2-2$ with $\left[\mathrm{X}_{1}\right]_{\mathrm{gs}}=3 \times 10^{11} \mathrm{~cm}^{-3}$ and $\left[X_{1}\right]_{\mathrm{gs}}=1 \times 10^{12} \mathrm{~cm}^{-3}$, respectively, (b) scenarios S3-3, S3-4 and S3-5 with $\left[X_{1}\right]_{\mathrm{gs}}=1 \times 10^{11} \mathrm{~cm}^{-3},\left[X_{1}\right]_{\mathrm{gs}}=3 \times 10^{11} \mathrm{~cm}^{-3}$ and $\left[X_{1}\right]_{\mathrm{gs}}=1 \times 10^{12} \mathrm{~cm}^{-3}$, respectively. For the other parameters, see text. The large and small squares refer to data reported by Ammann et al. (1998) and Ammann et al. (1997), respectively. The triangles refer to results reported by Gerecke et al. (1998). The small diamonds in (b) refer to experiments with diesel soot particles deposited on filters, as reported by Arens et al. (2001).

has to be replaced by:

$$
\begin{gathered}
L_{\mathrm{S}, \mathrm{X} 1}=k_{\mathrm{SLR} 1, \mathrm{X} 1, \mathrm{Y} 1}\left[\mathrm{X}_{1}\right]_{\mathrm{s}}\left[\mathrm{Y}_{1}\right]_{\mathrm{ss}} \\
+k_{\mathrm{SLR} 2, \mathrm{X} 1, \mathrm{X} 1}\left[\mathrm{X}_{1}\right]_{\mathrm{s}}\left[\mathrm{X}_{1}\right]_{\mathrm{s}}
\end{gathered}
$$

For the exemplary model simulations illustrated in Fig. 3, the following input parameters have been used in the iterative integration: $\omega_{\mathrm{X} 1}=3.6 \times 10^{4} \mathrm{~cm} \mathrm{~s}^{-1} ; \alpha_{\mathrm{s}, 0, \mathrm{X} 1}=10^{-3} ; \tau_{\mathrm{d}, \mathrm{X} 1}=18 \mathrm{~s}$;

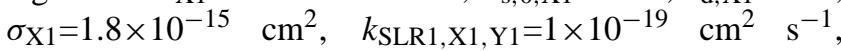
$k_{\mathrm{SLR} 2, \mathrm{X} 1, \mathrm{X} 1}=1 \times 10^{-19} \mathrm{~cm}^{2} \mathrm{~s}^{-1},\left[\mathrm{Y}_{1}\right]_{\mathrm{ss}, \mathrm{ini}}=1 \times 10^{15} \mathrm{~cm}^{-2}$, $\left[X_{1}\right]_{\mathrm{gs}}=2.5 \times 10^{12} \mathrm{~cm}^{-3}$ (scenario $\left.\mathrm{S} 3-1\right)$ or $2.5 \times 10^{13} \mathrm{~cm}^{-3}$ (scenario S3-2). $\omega_{\mathrm{X} 1}, \alpha_{\mathrm{S}, 0, \mathrm{X} 1}, \tau_{\mathrm{X} 1}$, and $\sigma_{\mathrm{X} 1}$ are based on experimental data for the adsorption of ozone at the surface of soot particles on time scales of seconds to minutes in Knudsen cell and flow tube studies (Stephens et al., 1986; Fendel et al., 1995; Rogaski et al., 1997; Pöschl et al., 2001; 


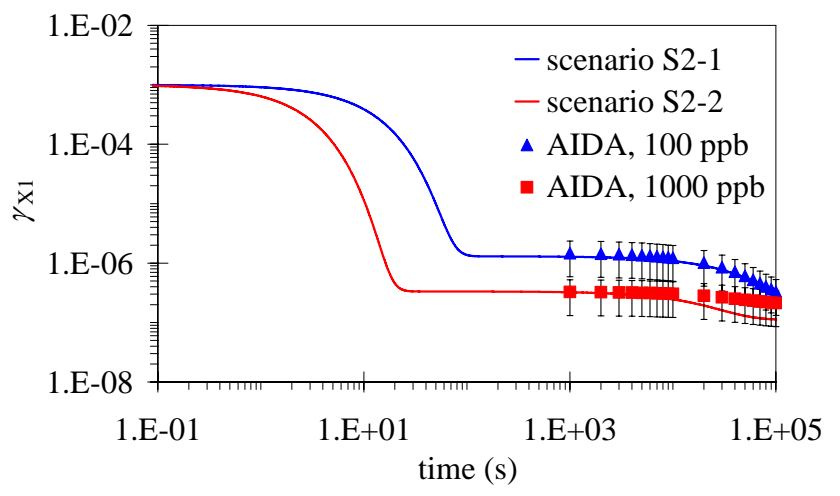

Fig. 3. Temporal evolution of the particle surface composition and the gas uptake coefficient in model system S3 (adsorption and parallel surface layer reactions including adsorbate self-reaction): scenario S3-1 with $\left[\mathrm{X}_{1}\right]_{\mathrm{gs}}=2.5 \times 10^{13} \mathrm{~cm}^{-3}$ and scenario S3-2 with $\left[\mathrm{X}_{1}\right]_{\mathrm{gs}}=2.5 \times 10^{12} \mathrm{~cm}^{-3}$. The symbols refer to aerosol chamber experiments by Kamm et al. (1999).

Sect. 2.1.1). $\left[\mathrm{Y}_{1}\right]_{\mathrm{ss}}$,ini approximates the surface concentration of aromatic rings on a graphene layer (or large polycyclic aromatic hydrocarbon). $k_{\mathrm{SLR} 1, \mathrm{X} 1, \mathrm{Y} 1}$ and $k_{\mathrm{SLR} 2, \mathrm{X} 1, \mathrm{X} 1}$ have been adjusted to fit the experimental data for ozone uptake on soot over a time scale of hours in aerosol chamber studies (Kamm et al., 1999; Fig. 3). Experiments by Longfellow et al. (2000) suggest that the initial uptake coefficient (surface assommodation coefficient) and the quasisteady-state uptake coefficient at reaction times of 1-7 h may be as high as $10^{-2}$ and $10^{-4}$, respectively, for ozone uptake on fresh methane soot. These observations could as well be simulated with the above model equations and different rate parameters or with a different set of reactions and equations more representative for the chemical composition and reactivity of the investigated surfaces. A comprehensive analysis and consolidation of all available studies of ozone uptake on soot, the identification of specific surface properties responsible for the differences observed in different experiments performed with different types of soot, and the planning and design of experiments (reaction conditions, time scales, etc.) for the development of consistent chemical mechanisms of soot surface reactions with ozone would go beyond the scope of this paper. Nevertheless, the above model simulations illustrate the applicability and usefulness of the PRA framework for this aim, which we are planning to pursue in future studies.

\subsection{Non-reactive gas uptake into liquid particles}

2.2.1 Model system Liquid 1 (L1): adsorption and solubility saturation

In model system $\mathrm{L} 1$ a trace gas $\mathrm{X}_{1}$ undergoes reversible adsorption and surface-bulk transport (solvation and desolvation) onto and into a liquid droplet, but no chemical reac- tions. Under these conditions, the general PRA surface mass balance and rate equations can be reduced to:

$$
\begin{aligned}
& \mathrm{d}\left[\mathrm{X}_{1}\right]_{\mathrm{s}} / \mathrm{d} t=J_{\mathrm{ads}, \mathrm{X} 1}-J_{\mathrm{des}, \mathrm{X} 1}+J_{\mathrm{b}, \mathrm{s}, \mathrm{X} 1}-J_{\mathrm{s}, \mathrm{b}, \mathrm{X} 1} \\
& J_{\mathrm{s}, \mathrm{b}, \mathrm{X} 1}=k_{\mathrm{s}, \mathrm{b}, \mathrm{X} 1}\left[\mathrm{X}_{1}\right]_{\mathrm{s}} \\
& J_{\mathrm{b}, \mathrm{s}, \mathrm{X} 1}=k_{\mathrm{b}, \mathrm{s}, \mathrm{X} 1}\left[\mathrm{X}_{1}\right]_{\mathrm{bs}} \\
& \alpha_{\mathrm{b}, \mathrm{X} 1}=\alpha_{\mathrm{s}, \mathrm{X} 1} \frac{J_{\mathrm{s}, \mathrm{b}, \mathrm{X} 1}}{J_{\mathrm{s}, \mathrm{b}, \mathrm{X} 1}+J_{\mathrm{des}, \mathrm{X} 1}}
\end{aligned}
$$

The rate equations and parameters describing adsorption, desorption, and net uptake of $\mathrm{X}_{1}$ are defined in the same way as in model system S1, Eqs. (11) to (15). Moreover, we assume that diffusion in the bulk liquid phase is fast and that the bulk phase is well mixed at all times, i.e. the nearsurface bulk concentration and average bulk concentration of $\mathrm{X}_{1}$ are identical $\left(\left[\mathrm{X}_{1}\right]_{\mathrm{bs}}=\left[\mathrm{X}_{1}\right]_{\mathrm{b}}\right)$. This is certainly the case for small particles with diameters of about $100 \mathrm{~nm}$ or less and small molecules with diffusion coefficients, $\mathrm{D}_{\mathrm{b}, \mathrm{X} 1}$, on the order of $10^{-5} \mathrm{~cm}^{2} \mathrm{~s}^{-1}$ or higher, leading to characteristic mixing times of $d_{\mathrm{p}}^{2} /\left(4 \pi^{2}\right) / D_{\mathrm{b}, \mathrm{X} 1} \approx 10^{-7} \mathrm{~s}$ (Seinfeld and Pandis, 1998). Under these conditions, mass balance for the bulk of a spherical particle (surface-to-volume ratio $6 / d_{\mathrm{p}}$ ) can simply be described by:

$\mathrm{d}\left[\mathrm{X}_{1}\right]_{\mathrm{b}} / \mathrm{d} t=\mathrm{d}\left[\mathrm{X}_{1}\right]_{\mathrm{bs}} / \mathrm{d} t=\left(J_{\mathrm{s}, \mathrm{b}, \mathrm{X} 1}-J_{\mathrm{b}, \mathrm{s}, \mathrm{X} 1}\right)\left(6 / d_{\mathrm{p}}\right)$

Note that the factor $6 / d_{\mathrm{p}}$, which is the surface-to-volume ratio of a spherical particle, converts the surface area normalized fluxes to a volume based rate of change. According to equations (PRA-72) and (PRA-73) the solubility saturation concentrations of $\mathrm{X}_{1}$ in the gas phase and particle bulk $\left(\left[\mathrm{X}_{1}\right]_{\mathrm{g} \text {, sat }}\right.$ and $\left.\left[\mathrm{X}_{1}\right]_{\mathrm{b} \text {,sat }}\right)$, and the gas-surface and surface-bulk transport rate parameters of $X_{1}$ under equilibrium conditions are related to its dimensionless gas-particle partitioning coefficient or solubility, $K_{\mathrm{sol}, \mathrm{cc}, \mathrm{X} 1}$ :

$K_{\mathrm{sol}, \mathrm{cc}, \mathrm{X} 1}=\frac{\left[\mathrm{X}_{1}\right]_{\mathrm{b}, \mathrm{sat}}}{\left[\mathrm{X}_{1}\right]_{\mathrm{g}, \mathrm{sat}}}=\frac{k_{\mathrm{s}, \mathrm{b}, \mathrm{X} 1}}{k_{\mathrm{b}, \mathrm{s}, \mathrm{X} 1}} \frac{\alpha_{\mathrm{s}, \mathrm{X} 1} \omega_{\mathrm{X} 1}}{4 k_{\mathrm{d}, \mathrm{X} 1}}$

At infinite dilution $K_{\text {sol,cc,X1 }}$ equals the Henry's law coefficient of $\mathrm{X}_{1}$ in the investigated condensed phase $\left(\left[\mathrm{X}_{1}\right]_{\mathrm{b}} \approx 0, \theta_{\mathrm{s}} \approx 0, \alpha_{\mathrm{s}, \mathrm{X} 1} \approx \alpha_{\mathrm{s}, 0, \mathrm{X} 1}, K_{\mathrm{sol}, \mathrm{cc}, \mathrm{X} 1} \approx H_{\mathrm{cc}, \mathrm{X} 1} ;\right.$ PRA Sect. 3.5.2). For the exemplary model simulations illustrated in Figs. 4 to 6, the following input parameters have been used in the iterative integration of Eqs. (18) and (22): $\alpha_{\mathrm{s}, 0, \mathrm{X} 1}=1 ; \omega_{\mathrm{X} 1}=3.1 \times 10^{4} \mathrm{~cm} \mathrm{~s}^{-1} ; \sigma_{\mathrm{X} 1}=1 \times 10^{-14} \mathrm{~cm}^{2}$; $\left[\mathrm{X}_{1}\right]_{\mathrm{s}, \text { ini }}=\left[\mathrm{X}_{1}\right]_{\mathrm{bs}, \text { ini }}=\left[\mathrm{X}_{1}\right]_{\mathrm{b}, \text { ini }}=0, d_{\mathrm{p}}=100 \mathrm{~nm}$. For $\tau_{\mathrm{d}, \mathrm{X} 1}$, $k_{\mathrm{s}, \mathrm{b}, \mathrm{X} 1}, k_{\mathrm{b}, \mathrm{s}, \mathrm{X} 1}$, and $\left[\mathrm{X}_{1}\right]_{\mathrm{gs}}$, which have been varied in scenarios L1-1 to L1-9, see Table 1. The scenarios L2-1 to L2-9, in which bulk diffusion is important and which are also listed in Table 1, will be discussed in Sect. 2.2.2.

The parameters for scenarios L1-1 to L1-3 are based on the experimental data reported by Jayne et al. (1990) for the uptake of sulfur dioxide into acidic aqueous solution droplets, assuming that the "surface complex" proposed in 
Table 1. Scenarios, rate parameters, and gas phase concentrations for the simulation of time dependent gas uptake into liquid particles for model systems L1 (bulk saturation) and L2 (bulk diffusion), respectively. $\tau_{\mathrm{d}, \mathrm{X} 1}$ is the desorption lifetime (which is the inverse of the first-order desorption rate coefficient) of $\mathrm{X}_{1}, k_{\mathrm{s}, \mathrm{b}, \mathrm{X} 1}$ and $k_{\mathrm{b}, \mathrm{s}, \mathrm{X} 1}$ are the first-order rate coefficients for surface-to-bulk and bulk-to-surface transfer of $\mathrm{X}_{1}$, respectively. $H_{\mathrm{cp}, \mathrm{X} 1}$ is the Henry's law coefficient of $\mathrm{X}_{1}$ and $H_{\mathrm{cc}, \mathrm{X} 1}$ is its dimensionless form, [X $]_{\mathrm{gs}}$ is the near-surface gas phase number concentration of $X_{1}$. The scenarios L1-1 to L1-9 and L2-1 and L2-9 are organized to represent three different settings of the kinetic parameters, while for each parameter setting three scenarios are defined by three different gas phase concentrations. Note that model systems L1 and L2 have identical kinetic parameter settings.

\begin{tabular}{lllllll}
\hline Scenario & $\begin{array}{l}\tau_{\mathrm{d}, \mathrm{X} 1} \\
(\mathrm{~s})\end{array}$ & $\begin{array}{l}k_{\mathrm{s}, \mathrm{b}} \\
\left(\mathrm{s}^{-1}\right)\end{array}$ & $\begin{array}{l}k_{\mathrm{b}, \mathrm{s}} \\
\left(\mathrm{cm} \mathrm{s}^{-1}\right)\end{array}$ & $\begin{array}{l}H_{\mathrm{cc}, \mathrm{X} 1} \\
(-)\end{array}$ & $\begin{array}{l}H_{\mathrm{cp}, \mathrm{X} 1} \\
\left(\mathrm{~mol} \mathrm{~L}^{-1} \mathrm{~atm}^{-1}\right)\end{array}$ & $\begin{array}{l}{\left[\mathrm{X}_{1}\right]_{\mathrm{gs}}} \\
\left(\mathrm{cm}^{-3}\right)\end{array}$ \\
\hline L1-1, L2-1 & $1.7 \times 10^{-5}$ & $7 \times 10^{3}$ & 7.5 & 126 & 5.15 & $1 \times 10^{11}$ \\
L1-2, L2-2 & $1.7 \times 10^{-5}$ & $7 \times 10^{3}$ & 7.5 & 126 & 5.15 & $1 \times 10^{13}$ \\
L1-3, L2-3 & $1.7 \times 10^{-5}$ & $7 \times 10^{3}$ & 7.5 & 126 & 5.15 & $1 \times 10^{15}$ \\
L1-4, L2-4 & $1.7 \times 10^{-5}$ & $7 \times 10^{5}$ & 7.5 & $1.26 \times 10^{4}$ & 515 & $1 \times 10^{11}$ \\
L1-5, L2-5 & $1.7 \times 10^{-5}$ & $7 \times 10^{5}$ & 7.5 & $1.26 \times 10^{4}$ & 515 & $1 \times 10^{13}$ \\
L1-6, L2-6 & $1.7 \times 10^{-5}$ & $7 \times 10^{5}$ & 7.5 & $1.26 \times 10^{4}$ & 515 & $1 \times 10^{15}$ \\
L1-7, L2-7 & 1 & $10^{4}$ & 1 & $7.84 \times 10^{7}$ & $3.2 \times 10^{6}$ & $1 \times 10^{11}$ \\
L1-8, L2-8 & 1 & $10^{4}$ & 1 & $7.84 \times 10^{7}$ & $3.2 \times 10^{6}$ & $1 \times 10^{13}$ \\
L1-9, L2-9 & 1 & $10^{4}$ & 1 & $7.84 \times 10^{7}$ & $3.2 \times 10^{6}$ & $1 \times 10^{15}$ \\
\hline
\end{tabular}

their study corresponds to an adsorbed molecule in the PRA framework. Here we assume that chemical reactions are negligible, which is reasonable for solutions sufficiently acidic to prevent significant formation of sulfite from $\mathrm{SO}_{2}$. The data of Jayne et al. (1990) did not allow to fully constrain $\alpha_{\mathrm{s}, 0, \mathrm{X} 1}$, but they reported rate parameters equivalent to $\tau_{\mathrm{d}, \mathrm{X} 1}$ and $k_{\mathrm{s}, \mathrm{b}, \mathrm{X} 1}$ for different assumptions of $\alpha_{\mathrm{s}, 0, \mathrm{X} 1}$. For scenarios L1-1 to L1-3 we have set $\alpha_{\mathrm{s}, 0, \mathrm{X} 1}$ to unity and used the corresponding values for $\tau_{\mathrm{d}, \mathrm{X} 1}$ and $k_{\mathrm{s}, \mathrm{b}, \mathrm{X} 1}$ based on Jayne et al. (1990). Using Eq. (23), the bulk-to-surface transport rate constant $k_{\mathrm{b}, \mathrm{s}, \mathrm{X} 1}$ for scenarios L1-1 to L1-3 was matched to a Henry's law coefficient or solubility at infinite dilution which roughly corresponds to that of $\mathrm{SO}_{2}$ at $\mathrm{pH} \sim 2$ $\left(K_{\mathrm{sol}, \mathrm{cp}, \mathrm{X} 1}=H_{\mathrm{cp}, \mathrm{X} 1}=5 \mathrm{~mol} \mathrm{\textrm {L } ^ { - 1 }} \mathrm{atm}^{-1}\right.$ for $\left.\alpha_{\mathrm{s}, \mathrm{X} 1}=\alpha_{\mathrm{s}, 0, \mathrm{X} 1}\right)$. Here and below Henry's law coefficient or solubilities in concentration and pressure units (index "cp") have been converted into the corresponding dimensionless parameters (index "cc") by the relation $K_{\mathrm{sol}, \mathrm{cc}, \mathrm{X} 1}=R T K_{\mathrm{sol}, \mathrm{cp}, \mathrm{X} 1}$ (PRA Sect. 3.5.2). Note that this choice of parameters is not meant to pursue a specific investigation of $\mathrm{SO}_{2}$ uptake into aqueous droplets in this paper but just to establish a reasonable base case and starting point for the parameter variations in the different scenarios of model system L1 (Table 1). So far we have found no other published experimental data suitable to retrieve these basic rate parameters, although Dijkaev and Tabazadeh (2003) pointed out the potential importance of surface saturation effects on gas-particle partitioning, in particular for organic surfactants.

In scenarios L1-4 to L1-6 and L1-7 to L1-9 (Table 1$), \tau_{\mathrm{X} 1}, k_{\mathrm{s}, \mathrm{b}, \mathrm{X} 1}$ and $k_{\mathrm{b}, \mathrm{s}, \mathrm{X} 1}$ have been varied to simulate species with different adsorption properties and solubilities. The parameters have been adjusted to match the following Henry's law coefficients or solubilities at $\alpha_{\mathrm{s}, \mathrm{X} 1}=\alpha_{\mathrm{s}, 0, \mathrm{X} 1}: H_{\mathrm{cp}, \mathrm{X} 1}=515 \mathrm{~mol} \mathrm{~L}^{-1} \mathrm{~atm}^{-1}$ (L1-4 to L1-6) and $H_{\mathrm{cp}, \mathrm{X} 1} \approx 3.2 \times 10^{6} \mathrm{~mol} \mathrm{~L}^{-1} \mathrm{~atm}^{-1}$ (L1-7 to L1-9).

Figure 4 shows the temporal evolution of the liquid phase bulk concentration $\left[\mathrm{X}_{1}\right]_{\mathrm{b}}$, sorption layer surface coverage $\theta_{\mathrm{s}}$, surface accommodation coefficient $\alpha_{\mathrm{s}, \mathrm{X} 1}$, bulk accommodation coefficient $\alpha_{\mathrm{b}, \mathrm{X} 1}$, and uptake coefficient $\gamma_{\mathrm{X} 1}$ for scenarios L1-1 to L1-3, respectively, in which $\left[\mathrm{X}_{1}\right]_{\mathrm{gs}}$ is varied from $1 \times 10^{11}$ to $1 \times 10^{15}$. In all scenarios except L1-7 (Fig. 6a), solubility saturation equilibrium is achieved $\left([\mathrm{X}]_{\mathrm{b}}=[\mathrm{X}]_{\mathrm{b}, \mathrm{sat}}\right)$ and $\gamma_{\mathrm{X} 1}$ drops to zero within less than one millisecond. Moreover, $\alpha_{\mathrm{b}, \mathrm{X} 1}$ is significantly lower than $\alpha_{\mathrm{s}, \mathrm{X} 1}$ because the rate of desorption is significantly higher than the rate of surface-to-bulk transport.

At low and moderate trace gas concentration levels (L11 and L1-2, Fig. $4 \mathrm{a}$ and $\mathrm{b}), \alpha_{\mathrm{s}, \mathrm{X} 1}$ and $\alpha_{\mathrm{b}, \mathrm{X} 1}$ are practically independent of time and $\left[\mathrm{X}_{1}\right]_{\mathrm{gs}}$, and also the temporal evolution of $\gamma_{\mathrm{X} 1}$ is essentially independent of $\left[\mathrm{X}_{1}\right]_{\mathrm{gs}}$. At high trace gas concentration (L1-3, Fig. 4c), however, $\alpha_{\mathrm{s}, \mathrm{X} 1}$ and $\alpha_{\mathrm{b}, \mathrm{X} 1}$ decrease from their initial values characteristic for $\theta_{\mathrm{s}}=0$ to a lower value at equilibrium, which is due to surface saturation effects $\left(\theta_{\mathrm{S}}\right.$ close to scenarios L1-4 to L1-6, which are analogous to L1-1 to L1-3 except that $k_{\mathrm{s}, \mathrm{b}, \mathrm{X} 1}$ was increased by a factor of 100 (Table 1). These parameters correspond to a Henry's law coefficient a factor of 100 higher than for the base case, and thus solubility saturation is reached significantly later (after $\sim 1 \mathrm{~ms}$ for the lower concentration levels). Moreover, the increase of $k_{\mathrm{s}, \mathrm{b}, \mathrm{X} 1}$ makes the rate of surfaceto-bulk transport substantially higher than that of desorption, leading to a bulk accommodation coefficient just slightly lower than the surface accommodation coefficient. 

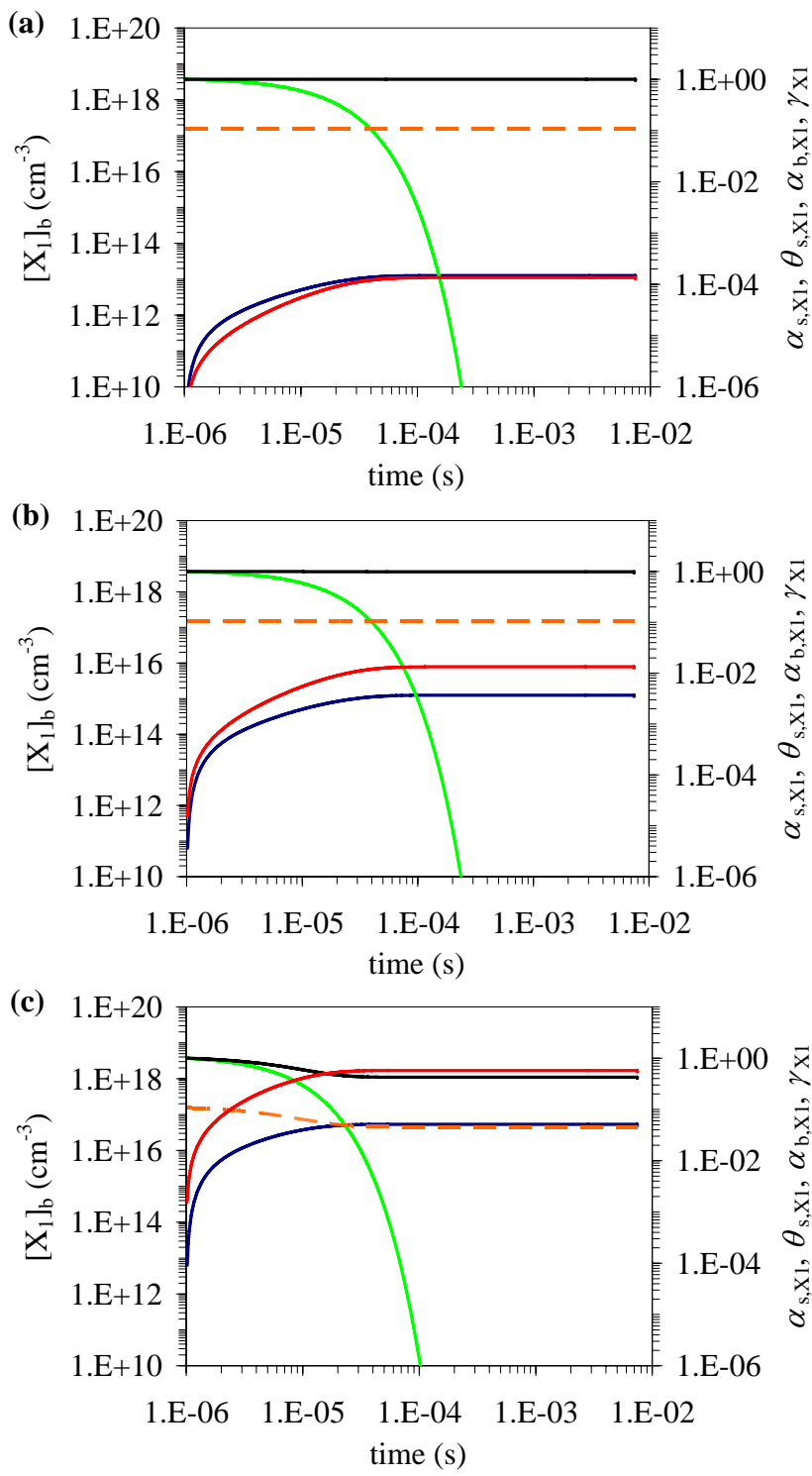

Fig. 4. Temporal evolution of sorption layer surface coverage $\theta_{\mathrm{s}, \mathrm{X} 1}$ (red), surface accommodation coefficient $\alpha_{\mathrm{s}, \mathrm{X} 1}$ (black), bulk accommodation coefficient $\alpha_{\mathrm{b}, \mathrm{X} 1}$ (orange), uptake coefficient $\gamma_{\mathrm{X} 1}$ (green) and particle bulk composition (blue) in model system L1 describing adsorption and surface-bulk transport of a trace gas $\mathrm{X}_{1}$ (i.e., non-reactive solvation of a trace gas into a liquid aerosol): scenario L1-1 (a) with $\left[\mathrm{X}_{1}\right]_{\mathrm{gs}}=1 \times 10^{11} \mathrm{~cm}^{-3}$, scenario L1-2 (b) with $\left[X_{1}\right]_{\mathrm{gs}}=1 \times 10^{13} \mathrm{~cm}^{-3}$ and scenario L1-3 (c) with $\left[\mathrm{X}_{1}\right]_{\mathrm{gs}}=1 \times 10^{15} \mathrm{~cm}^{-3}$. The further parameters associated with these scenarios are listed in Table 1. The temporal evolution for the other scenarios of model system L1 listed in Table 1, L1-4 to L1-6 and L1-7 to L1-9, are presented in Figs. 5 and 6, respectively.

In scenarios L1-7 to L1-9 (Fig. 6) $\tau_{\mathrm{d}, \mathrm{X} 1}$ was increased by almost five orders of magnitude whereas $k_{\mathrm{s}, \mathrm{b}, \mathrm{X} 1}$ and $\mathrm{k}_{\mathrm{b}, \mathrm{s}, \mathrm{X} 1}$ have been reduced by about one order of magnitude, enhancing the Henry's law coefficient by almost four orders
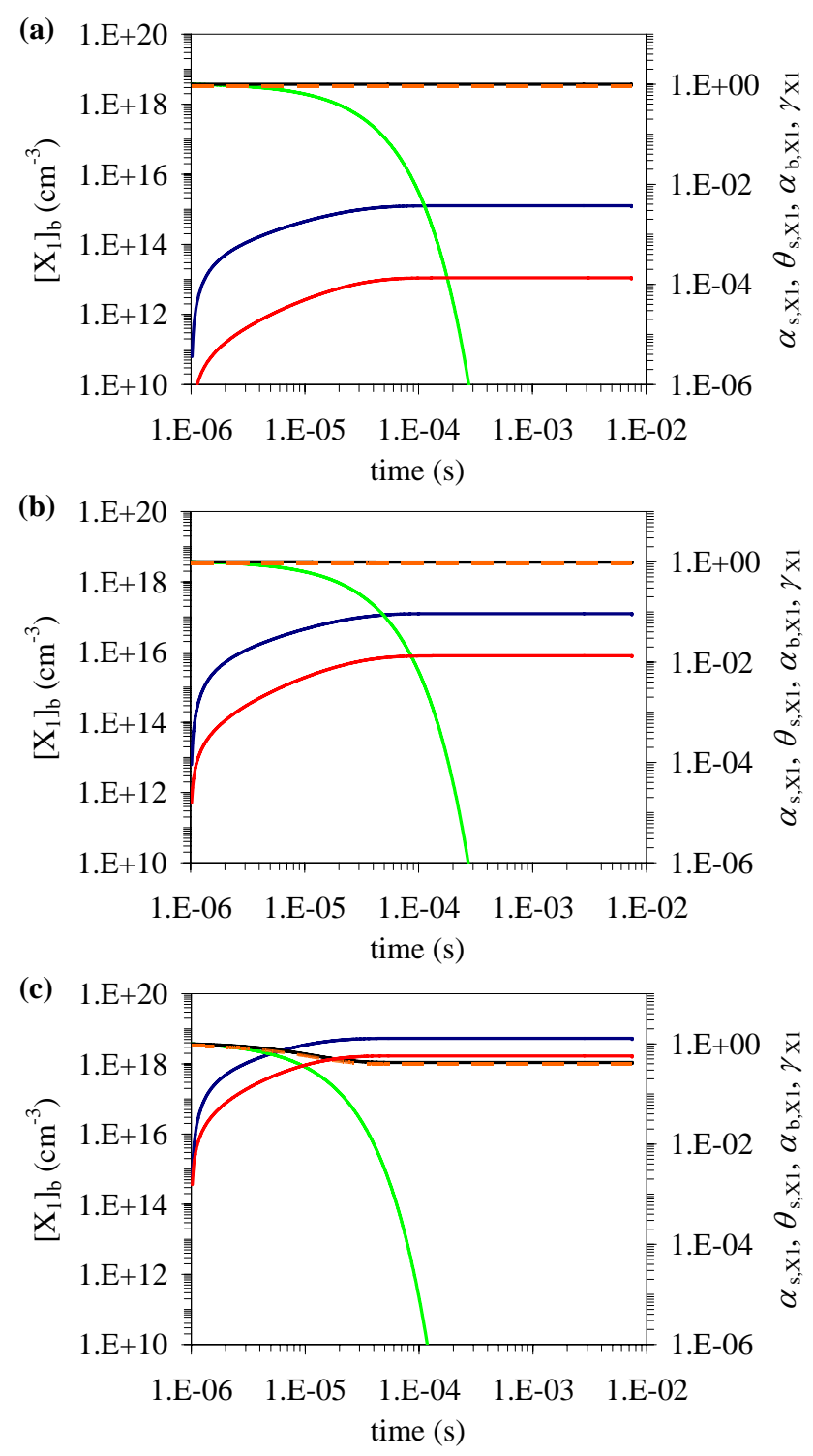

Fig. 5. Temporal evolution of sorption layer surface coverage $\theta_{\mathrm{s}, \mathrm{X} 1}$ (red), surface accommodation coefficient $\alpha_{\mathrm{s}, \mathrm{X} 1}$ (black), bulk accommodation coefficient $\alpha_{\mathrm{b}, \mathrm{X} 1}$ (orange), uptake coefficient $\gamma_{\mathrm{X} 1}$ (green) and particle bulk composition (blue) in model system L1 describing adsorption and surface-bulk transport of a trace gas $\mathrm{X}_{1}$ (i.e., non-reactive solvation of a trace gas into a liquid aerosol): scenario L1-4 (a) with $\left[\mathrm{X}_{1}\right]_{\mathrm{gs}}=1 \times 10^{11} \mathrm{~cm}^{-3}$, scenario L1-5 (b) with $\left[\mathrm{X}_{1}\right]_{\mathrm{gs}}=1 \times 10^{13} \mathrm{~cm}^{-3}$ and scenario L1-6 (c) with $\left[\mathrm{X}_{1}\right]_{\mathrm{gs}}=1 \times 10^{15} \mathrm{~cm}^{-3}$.

of magnitude relative to scenarios L1-4 to L1-6 (Table 1). These parameters represent a highly viscous particle interacting with a highly soluble gas with strong affinity to the surface, leading to very high saturation surface coverages $\left(\theta_{\mathrm{s}} \approx 1\right)$ at all gas phase concentrations and very slow solubility saturation at low concentration (after $\sim 1 \mathrm{~s}$ in L1-7, 
Fig. 6a). Due to the high value of $\tau_{\mathrm{d}, \mathrm{X} 1}$ the rate of desorption is much lower than that of surface-to-bulk transport, and $\alpha_{\mathrm{b}, \mathrm{X} 1}$ equals $\alpha_{\mathrm{s}, \mathrm{X} 1}$ at all times and concentration levels. Moreover, surface saturation effects and the decrease from initial to equilibrium values of $\alpha_{\mathrm{s}, \mathrm{X} 1}$ and $\alpha_{\mathrm{b}, \mathrm{X} 1}$ is particularly pronounced in L1-9 (Fig. 6c), which also clearly illustrates that $\alpha_{\mathrm{s}, \mathrm{X} 1}$ limits both $\alpha_{\mathrm{b}, \mathrm{X} 1}$ and $\gamma_{\mathrm{X} 1}$ (provided that gassurface reactions are negligible; PRA Sect. 3.6).

Overall, the numerical simulations performed for model system L1 demonstrate that adsorption and surface saturation effects (limitation of surface accommodation by sorption layer capacity) can significantly influence $\alpha_{\mathrm{b}, \mathrm{X} 1}$ and $\alpha_{\mathrm{s}, \mathrm{X} 1}$ even in case of non-reactive uptake of highly soluble trace gases by liquid particles. The most important rate parameters governing these effects are the desorption lifetime and the surface-to-bulk transfer rate coefficient. Besides the temporal evolution of gas uptake they also influence the equilibrium values of solubility, especially at elevated trace gas concentrations.

In all scenarios except L1-7, equilibrium surface and bulk concentrations are largely established by $0.01 \mathrm{~s}$ (upper limit of time scale in Figs. 4-6). Due to the decrease of $\alpha_{\mathrm{s}, \mathrm{X} 1}$ and $\alpha_{\mathrm{b}, \mathrm{X} 1}$ at solubility saturation, however, the increase of $\left[\mathrm{X}_{1}\right]_{\mathrm{b} \text {, sat }}$ is less than proportional to that of $\left[\mathrm{X}_{1}\right]_{\mathrm{g} \text {,sat }}$ from L12 to L1-3 (Fig. 4b vs. c) and from L1-5 to L1-6 (Fig. 5b vs. c). From scenario L1-8 to scenario L1-9 (Fig. 6b vs. c; 0.01 s) almost no increase of the equilibrium bulk concentration is observed, in spite of the gas phase concentration increase by two orders of magnitude. These deviations from Henry's law and non-linear dependencies of solubility on gas phase composition will be illustrated and addressed in more detail below by exemplary calculations of $K_{\mathrm{sol}, \mathrm{cp}, \mathrm{X} 1}$ as a function of $\alpha_{\mathrm{s}, 0, \mathrm{X} 1}, k_{\mathrm{d}, \mathrm{X} 1}, k_{\mathrm{s}, \mathrm{b}, \mathrm{X} 1}, k_{\mathrm{b}, \mathrm{s}, \mathrm{X} 1}$, and [ $\left.\mathrm{X}_{\mathrm{i}}\right]_{\mathrm{gs}}$ (model system SS6, Sect. 3.6).

\subsubsection{Model system Liquid 2 (L2): adsorption and bulk dif- fusion}

Model system L2 is analogous to L1, except for considering large droplets where the gas uptake is influenced by liquid phase diffusion. Assuming that the particle bulk is initially free of $X_{1}$, the net transport flux of $X_{1}$ from the surface to the near-surface particle bulk, $J_{\mathrm{s}, \mathrm{b}, \text { net,X1 } 1}$, can be matched with a quasi-steady-state dissolvo-diffusive flux of $X_{1}$ from the near-surface particle bulk towards the particle core, $J_{\mathrm{b}, \mathrm{dd}, \mathrm{X} 1}$ (analogous to the reacto-diffusive flux in systems with chemical reactions in the particle bulk; PRA Sect. 3.5.1), and approximated by (Finlayson-Pitts and Pitts, 2000; assumption of quasi-planar surface geometry):

$$
\begin{aligned}
& J_{\mathrm{s}, \mathrm{b}, \text { net }, \mathrm{X} 1}=J_{\mathrm{s}, \mathrm{b}, \mathrm{X} 1}-J_{\mathrm{b}, \mathrm{s}, \mathrm{X} 1}=J_{\mathrm{b}, \mathrm{dd}, \mathrm{X} 1} \\
& =\left(D_{\mathrm{b}, \mathrm{X} 1} /(\pi t)\right)^{1 / 2}\left[\mathrm{X}_{1}\right]_{\mathrm{bs}}=k_{\mathrm{s}, \mathrm{b}, \mathrm{net}, \mathrm{X} 1}\left[\mathrm{X}_{1}\right]_{\mathrm{s}} \\
& k_{\mathrm{s}, \mathrm{b}, \mathrm{net}, \mathrm{X} 1}=k_{\mathrm{s}, \mathrm{b}, \mathrm{X} 1}\left(1+\frac{k_{\mathrm{b}, \mathrm{s}, \mathrm{X} 1}}{\sqrt{D_{\mathrm{b}, \mathrm{X} 1} /(\pi t)}}\right)^{-1}
\end{aligned}
$$
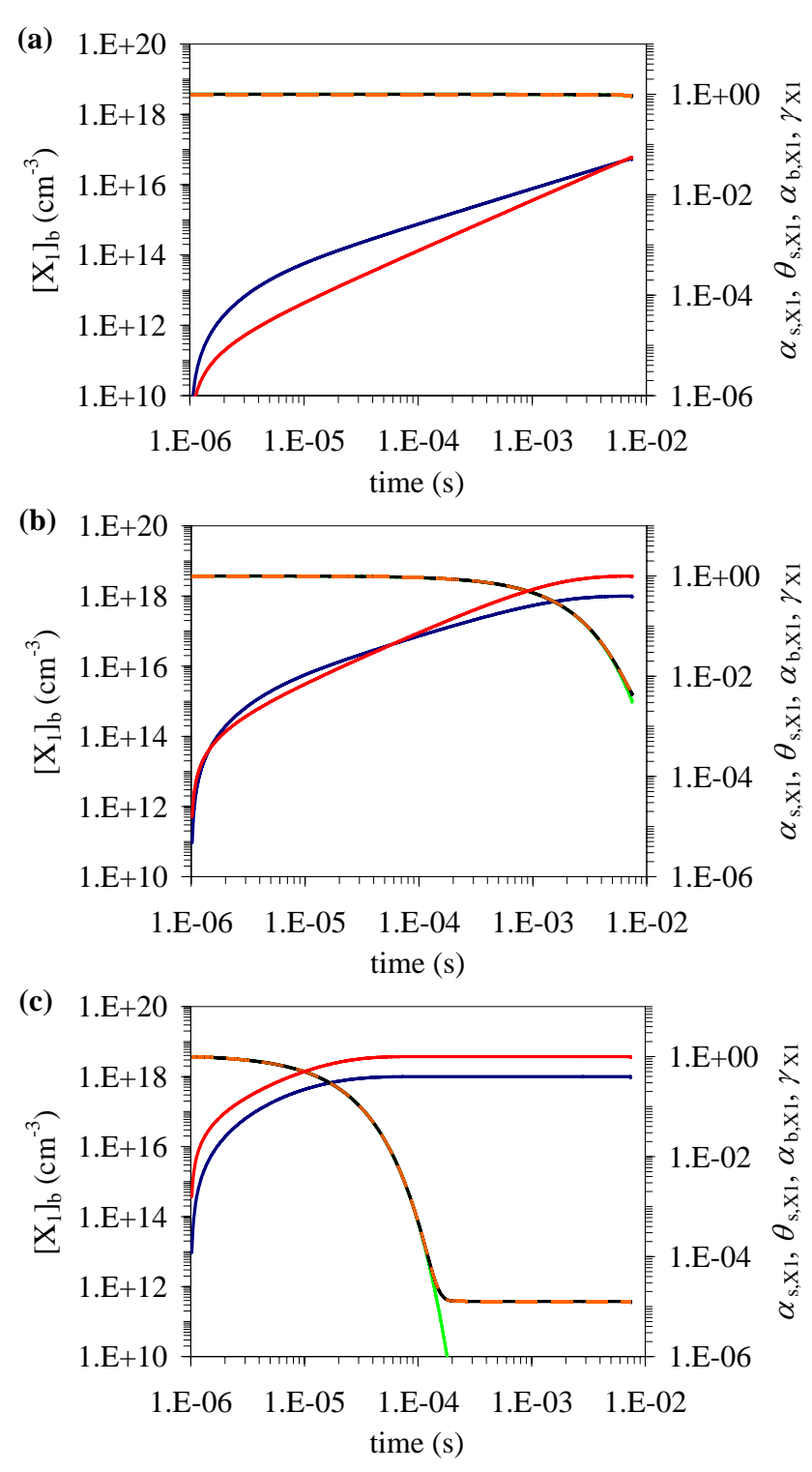

Fig. 6. Temporal evolution of sorption layer surface coverage $\theta_{\mathrm{s}, \mathrm{X} 1}$ (red), surface accommodation coefficient $\alpha_{\mathrm{s}, \mathrm{X} 1}$ (black), bulk accommodation coefficient $\alpha_{\mathrm{b}, \mathrm{X} 1}$ (orange), uptake coefficient $\gamma_{\mathrm{X} 1}$ (green) and particle bulk composition (blue) in model system L1 describing adsorption and surface-bulk transport of a trace gas $\mathrm{X}_{1}$ (i.e., non-reactive solvation of a trace gas into a liquid aerosol): scenario L1-7 (a) with $\left[\mathrm{X}_{1}\right]_{\mathrm{gs}}=1 \times 10^{11} \mathrm{~cm}^{-3}$, scenario L1-8 (b) with $\left[\mathrm{X}_{1}\right]_{\mathrm{gs}}=1 \times 10^{13} \mathrm{~cm}^{-3}$ and scenario L1-9 (c) with $\left[\mathrm{X}_{1}\right]_{\mathrm{gs}}=1 \times 10^{15} \mathrm{~cm}^{-3}$.

Equation (24) can be inserted for $\left(J_{\mathrm{s}, \mathrm{b}, \mathrm{X} 1}-J_{\mathrm{b}, \mathrm{s}, \mathrm{X} 1}\right)$ in Eq. (18) to describe the surface mass balance in model system L2 in analogy to model system L1. The ratio of the near-surface bulk and surface concentrations of $X_{1}$ can be obtained for quasi-steady state conditions and in analogy to 

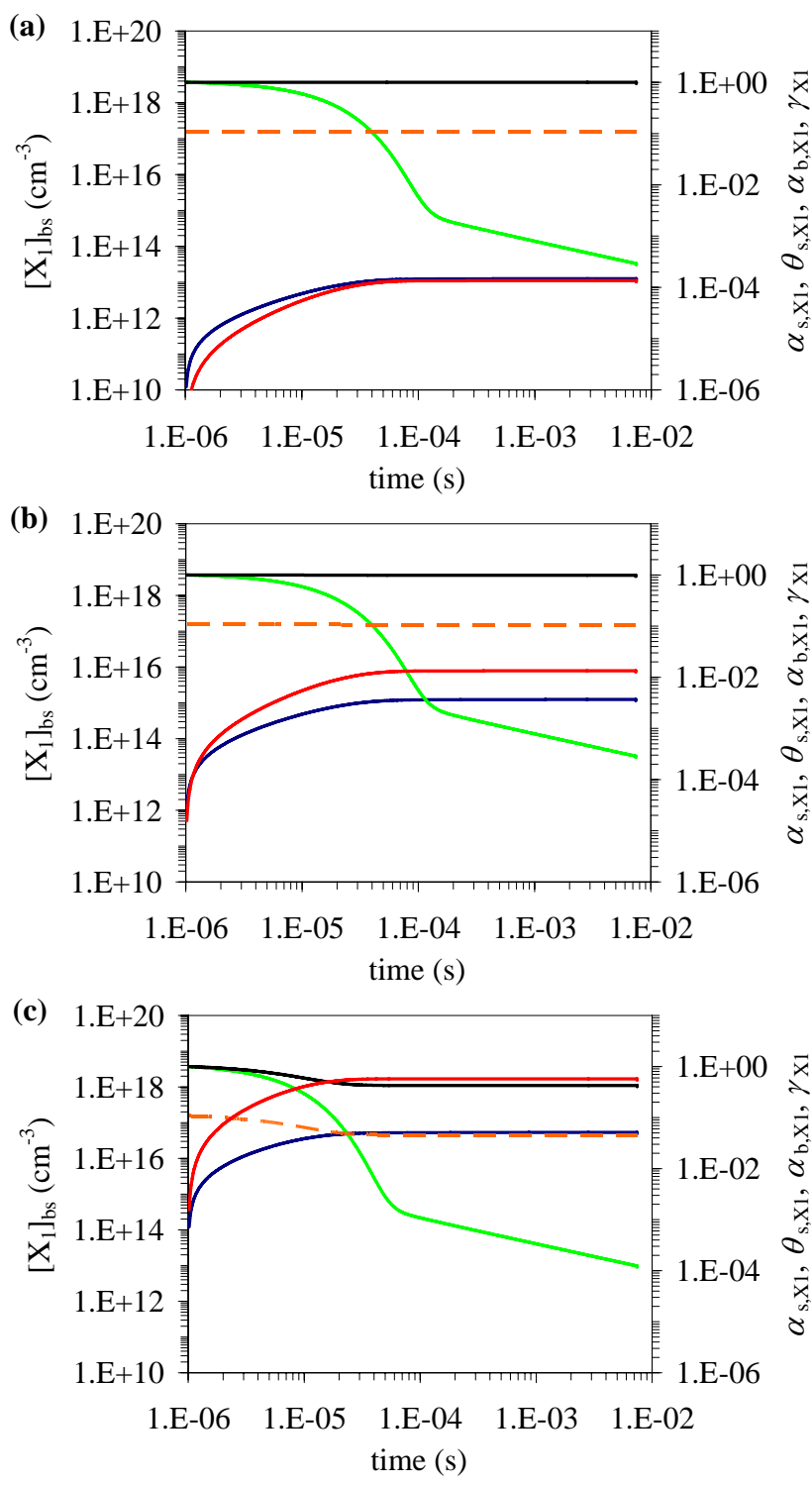

Fig. 7. Temporal evolution of sorption layer surface coverage $\theta_{\mathrm{s}, \mathrm{X} 1}$ (red), surface accommodation coefficient $\alpha_{\mathrm{s}, \mathrm{X} 1}$ (black), bulk accommodation coefficient $\alpha_{\mathrm{b}, \mathrm{X} 1}$ (orange), uptake coefficient $\gamma_{\mathrm{X} 1}$ (green) and particle bulk composition (blue) in model system L2 describing adsorption and diffusion-limited surface-bulk transport of a trace gas $\mathrm{X}_{1}$ (i.e., non-reactive solvation of a trace gas into a liquid aerosol): scenario L2-1 (a) with $\left[\mathrm{X}_{1}\right]_{\mathrm{gs}}=1 \times 10^{11} \mathrm{~cm}^{-3}$, scenario L2-2 (b) with $\left[\mathrm{X}_{1}\right]_{\mathrm{gs}}=1 \times 10^{13} \mathrm{~cm}^{-3}$ and scenario L2-3 (c) with $\left[X_{1}\right]_{\mathrm{gs}}=1 \times 10^{15} \mathrm{~cm}^{-3}$. The further parameters associated with these scenarios are listed in Table 1 . The temporal evolution for the other scenarios of model system L2 listed in Table 1, L2-4 to L2-6 and L2-7 to L2-9, are presented in Figures 8 and 9, respectively.

\section{Eq. (PRA-69):}

$\frac{\left[\mathrm{X}_{1}\right]_{\mathrm{bs}}}{\left[\mathrm{X}_{1}\right]_{\mathrm{s}}}=\frac{k_{\mathrm{s}, \mathrm{b}, \mathrm{X} 1}}{k_{\mathrm{b}, \mathrm{s}, \mathrm{X} 1}+\sqrt{D_{\mathrm{b}, \mathrm{X} 1} /(\pi t)}}$
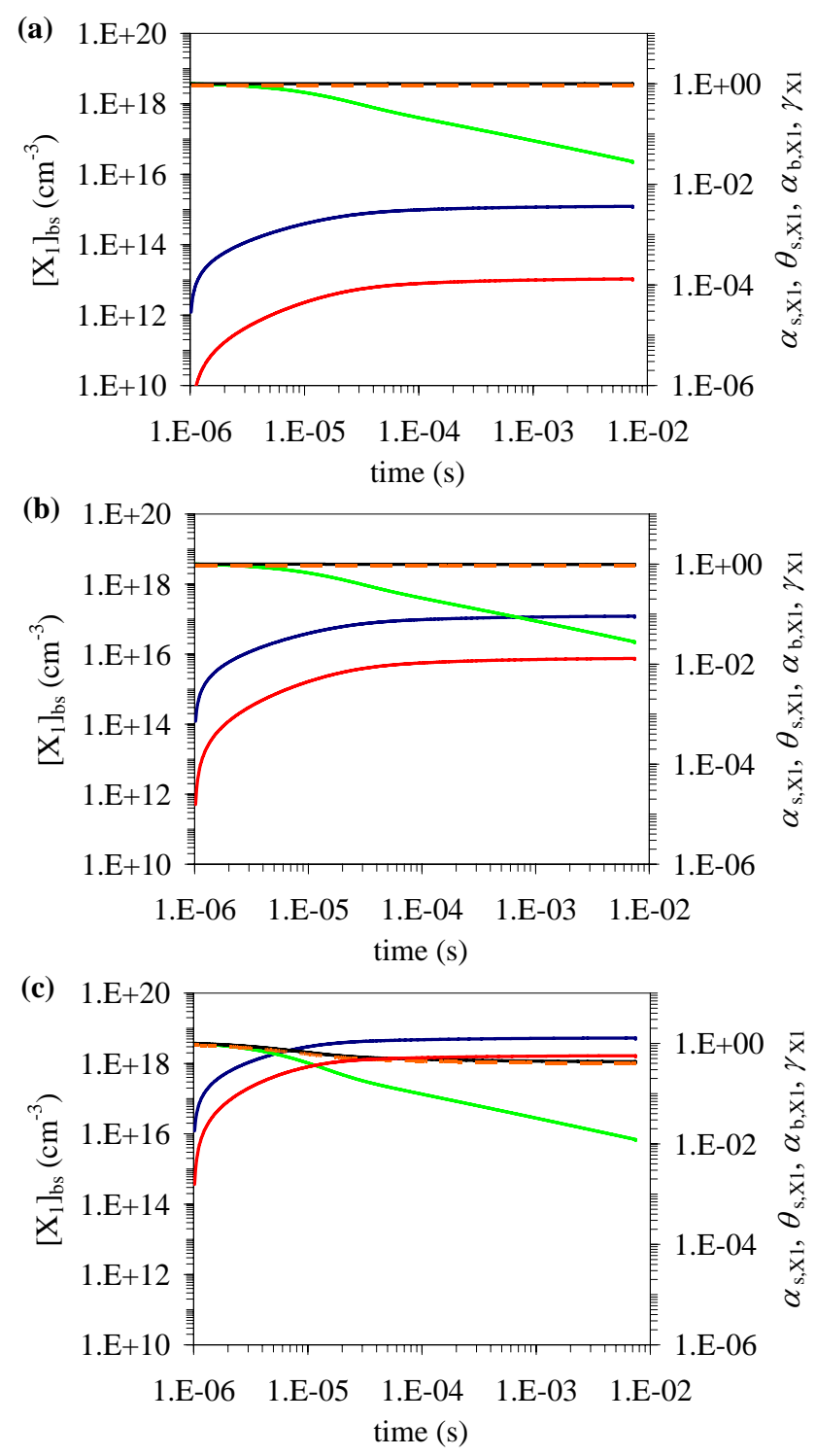

Fig. 8. Temporal evolution of sorption layer surface coverage $\theta_{\mathrm{s}, \mathrm{X} 1}$ (red), surface accommodation coefficient $\alpha_{\mathrm{s}, \mathrm{X} 1}$ (black), bulk accommodation coefficient $\alpha_{\mathrm{b}, \mathrm{X} 1}$ (orange), uptake coefficient $\gamma_{\mathrm{X} 1}$ (green) and particle bulk composition (blue) in model system L2 describing adsorption and diffusion-limited surface-bulk transport of a trace gas $\mathrm{X}_{1}$ (i.e., non-reactive solvation of a trace gas into a liquid aerosol): scenario L2-4 (a) with $\left[\mathrm{X}_{1}\right]_{\mathrm{gs}}=1 \times 10^{11} \mathrm{~cm}^{-3}$, scenario L2-5 (b) with $\left[\mathrm{X}_{1}\right]_{\mathrm{gs}}=1 \times 10^{13} \mathrm{~cm}^{-3}$ and scenario L2-6 (c) with $\left[\mathrm{X}_{1}\right]_{\mathrm{gs}}=1 \times 10^{15} \mathrm{~cm}^{-3}$.

Much more elaborate formlisms for the description of time dependent diffusive transport in liquid droplets considering particle size and geometry are available (e.g., Hanson, 1995; Worsnop et al., 2002; Smith et al., 2003) and can be inserted into the PRA framework (PRA Sect. 3.5). In the context of this paper, however, the simple approximations outlined above appear sufficient to demonstrate the potential effects 
of reversible adsorption and liquid phase diffusion on solubility saturation of large droplets.

For the exemplary model simulations illustrated in Figs. 79, the input parameters used in the iterative integration of Eq. (18) for scenarios L2-1 to L2-9 are the same that have been used for scenarios L1-1 to L1-9, except for assuming a larger particle diameter $\left(d_{\mathrm{p}} \gg 100 \mathrm{~nm}\right)$ : $\alpha_{\mathrm{s}, 0, \mathrm{X} 1}=1 ; \quad \omega_{\mathrm{X} 1}=3.1 \times 10^{4} \mathrm{~cm} \mathrm{~s}^{-1} ; \quad \sigma_{\mathrm{X} 1}=1 \times 10^{-14} \mathrm{~cm}^{2}$; $\left[\mathrm{X}_{1}\right]_{\mathrm{s}, \text { ini }}=\left[\mathrm{X}_{1}\right]_{\mathrm{b}, \text { ini }}=0$. For $\tau_{\mathrm{X} 1}, k_{\mathrm{s}, \mathrm{b}, \mathrm{X} 1}, k_{\mathrm{b}, \mathrm{s}, \mathrm{X} 1}$, and $\left[\mathrm{X}_{1}\right]_{\mathrm{gs}}$, see Table 1 . The particle is assumed to be large enough that the concentration of $\mathrm{X}_{1}$ in the particle core remains close to zero over the simulation time scale, justifying the simple form of the dissolvo-diffusive flux introduced above and the use of Eq. (24) (Finlayson-Pitts and Pitts, 2000). For the liquid phase diffusion coefficient we have chosen the same value as used by Jayne et al. (1990) for $\mathrm{SO}_{2}$ in acidic aqueous droplets, $D_{\mathrm{b}, \mathrm{X} 1}=7.65 \times 10^{-6} \mathrm{~cm}^{2} \mathrm{~s}^{-1}$. In scenarios L2-1 to L2-9 the near-surface bulk concentration of $X_{1},\left[X_{1}\right]_{b s}$, has been calculated iteratively using Eq. (26), based on the assumption of quasi-steady-state for the near-surface bulk of the large particle, whereas in scenarios L1-1 to L1-9 the bulk concentration of $\mathrm{X}_{1}$, had been obtained by explicitly solving the bulk mass balance equation for a well-mixed small particle $\left(\left[\mathrm{X}_{1}\right]_{\mathrm{b}}=\left[\mathrm{X}_{1}\right]_{\mathrm{bs}}\right)$.

Figures 7-9 (L2-1 to L2-9) are organized in analogy to Figs. 4-6 (L1-1 to L1-9), i.e. the scenario with the lowest gas phase concentration is displayed at the top (panel a), followed by the corresponding scenarios with gas phase concentrations enhanced by factors of 100 (panels b and c; Table 1). Note, however, that Figs. 7-9 display the near-surface bulk concentration of $\mathrm{X}_{1}$, while Figs. 4-6 display its bulk concentration.

The temporal evolution and values of the sorption layer surface coverage $\theta_{\mathrm{s}}$, the surface accommodation coefficient $\alpha_{\mathrm{s}, \mathrm{X} 1}$, and the bulk accommodation coefficient $\alpha_{\mathrm{b}, \mathrm{X} 1}$ are very similar in the corresponding scenarios of model systems L2 and L1 (Figs. 7-9 and 4-6, respectively), which is due to the identical basic rate coefficients for the processes governing surface mass balance and composition $\left(\alpha_{\mathrm{s}, 0, \mathrm{X} 1}, \tau_{\mathrm{X} 1}, k_{\mathrm{s}, \mathrm{b}, \mathrm{X} 1}\right.$, $\left.k_{\mathrm{b}, \mathrm{s}, \mathrm{X} 1}\right)$. The evolution of $\left[\mathrm{X}_{1}\right]_{\mathrm{bs}}$ in scenarios L2-1 to L2-9 is also very similar to that of $\left[\mathrm{X}_{1}\right]_{\mathrm{b}}$ in scenarios L1-1 to L19 , i.e. solubility-driven gas uptake into the near-surface bulk of large particles proceeds essentially in the same way as the solubility saturation of small well-mixed particles (approaching Henry's law equilibrium at long times and low concentrations). At very short times up to $10^{-5}-10^{-4} \mathrm{~s}$, the uptake coefficients $\gamma_{\mathrm{X} 1}$ of scenarios L2-1 to L2-9 also closely follow the temporal evolution of $\gamma_{\mathrm{X} 1}$ in scenarios L1-1 to L1-9. At the time scale of milliseconds $\left(10^{-4}-10^{-2} \mathrm{~s}\right)$, however, where $\gamma_{\mathrm{X} 1}$ rapidly drops to zero for small particles due to solubility saturation (scenarios L1-1 to L1-9; Figs. 4-6), the net gas uptake into large particles continues and $\gamma_{\mathrm{X} 1}$ exhibits only a slow decrease proportional to $\left(D_{\mathrm{b}, \mathrm{X} 1} \mathrm{t}\right)^{-1 / 2}$ (scenarios L2-1 to L2-9; Figs. 7-9; liquid phase diffusion towards the particle core). A similar case of the time dependence of the
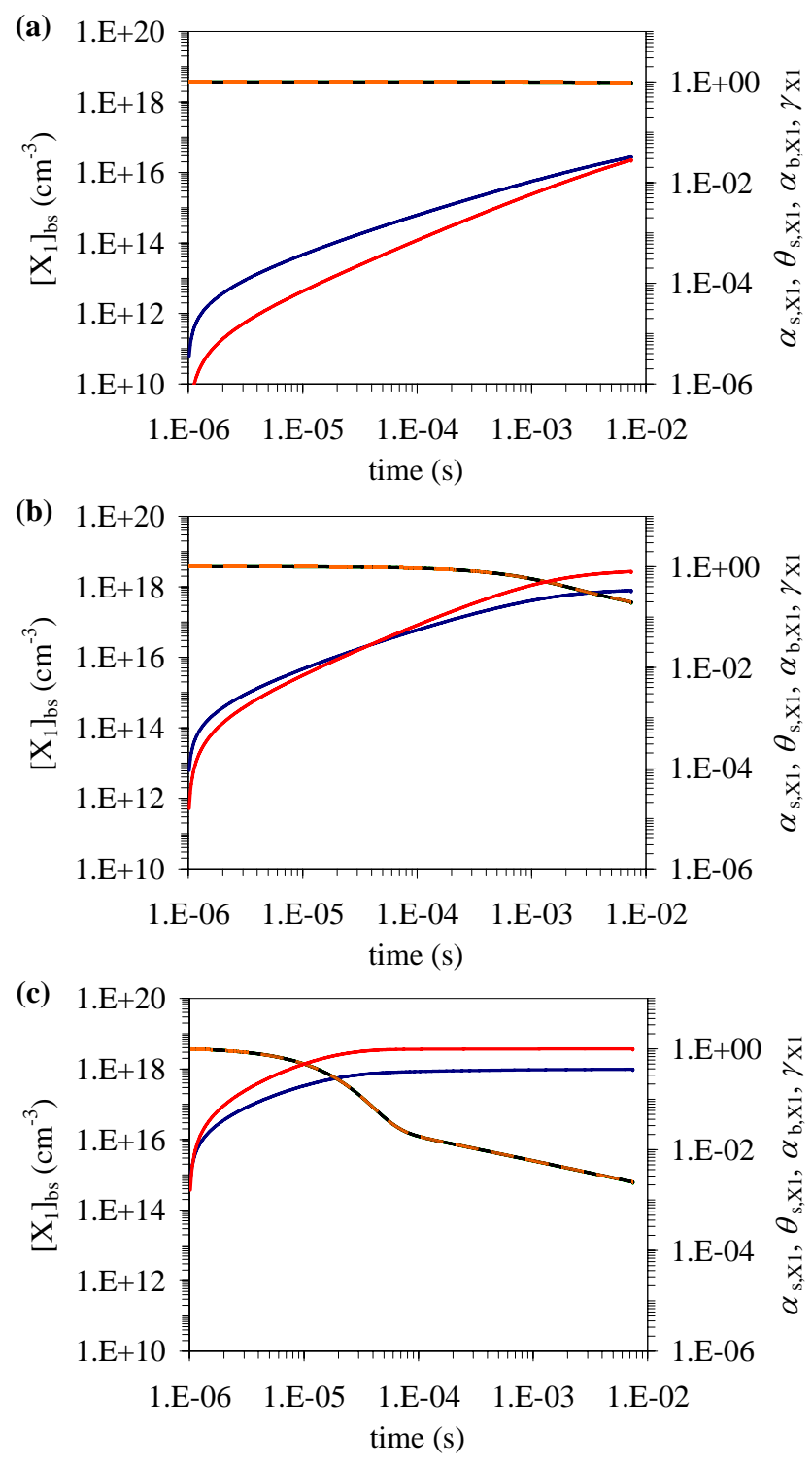

Fig. 9. Temporal evolution of sorption layer surface coverage $\theta_{\mathrm{s}, \mathrm{X} 1}$ (red), surface accommodation coefficient $\alpha_{\mathrm{s}, \mathrm{X} 1}$ (black), bulk accommodation coefficient $\alpha_{\mathrm{b}, \mathrm{X} 1}$ (orange), uptake coefficient $\gamma_{\mathrm{X} 1}$ (green) and particle bulk composition (blue) in model system L2 describing adsorption and diffusion-limited surface-bulk transport of a trace gas $\mathrm{X}_{1}$ (i.e., non-reactive solvation of a trace gas into a liquid aerosol): scenario L2-7 (a) with $\left[X_{1}\right]_{\mathrm{gs}}=1 \times 10^{11} \mathrm{~cm}^{-3}$, scenario L2-8 (b) with $\left[\mathrm{X}_{1}\right]_{\mathrm{gs}}=1 \times 10^{13} \mathrm{~cm}^{-3}$ and scenario L2-9 (c) with $\left[\mathrm{X}_{1}\right]_{\mathrm{gs}}=1 \times 10^{15} \mathrm{~cm}^{-3}$.

uptake coefficient driven by bulk phase diffusion has been presented by Hanson (1997) and Huthwelker et al. (2006) to parameterize uptake of acidic species into ice.

Overall, the initial non-linear increase of surface and near-surface bulk concentrations and the coincident decrease of the kinetic parameters $\alpha_{\mathrm{s}, \mathrm{X} 1}, \alpha_{\mathrm{b}, \mathrm{X} 1}, \gamma_{\mathrm{X} 1}$ in both model 
systems and sets of scenarios (L2 and L1) are determined by adsorption and surface saturation effects, whereas the establishment of constant equilibrium conditions at the end of the simulations for model system L1 and the continued gas uptake in the simulations for model system L2 are due to solubility saturation of the particle bulk (without or with limitation by liquid phase diffusion, respectively).

As mentioned above, the simulations L2-1 to L2-3 cover the conditions and time scale of the droplet train experiments by Jayne et al. (1990). If we compare the uptake coefficient at $10^{-3} \mathrm{~s}$ for the different gas phase concentrations, the numerical simulations predict a drop of $\gamma_{\mathrm{X} 1}$ by a factor of $\sim 2$ from L2-2 to L2-3 (Fig. 7b and c, respectively). This drop is consistent with the drop observed in the experiments by Jayne et al. (1990), when the gas phase concentration was changed from $10^{13}$ to $10^{15} \mathrm{~cm}^{-3}$.

\section{Gas phase concentration dependencies under steady- state conditions}

Reversible and competitive adsorption on a quasi-static surface implies that the surface accommodation coefficient of every species $X_{i}$ decreases with increasing surface concentration and thus with increasing gas phase concentration of all competitively co-adsorbing species. Consequently, all kinetic parameters proportional to $\alpha_{\mathrm{s}, \mathrm{Xi}}$, including bulk accommodation and sorption uptake coefficients $\left(\alpha_{\mathrm{Xi}}\right.$ and $\gamma_{\mathrm{sor}, \mathrm{Xi}}$, respectively) will also exhibit a dependence on gas phase composition, which can only be neglected when the total sorption layer surface coverage is much less than unity $\left(\theta_{\mathrm{s}} \ll 1\right.$; PRA Sect. 4.5.1).

To illustrate characteristic effects of gas phase concentrations and basic rate parameters on surface concentrations, surface and bulk mass accommodation coefficients, and uptake coefficients of trace gases under (quasi-)steady-state conditions, we present exemplary simulations based on PRA Sect. 4.5.1 (adsorption-reaction steady-state, Special Case B) for selected model systems and scenarios. Steady-state conditions are not only highly relevant for the determination of basic rate coefficients in laboratory experiments with aerosol and cloud model systems, quasi-steady-state conditions also do occur the temporal evolution of real time-dependent systems. For example, such conditions are illustrated by the plateau values of near-constant uptake coefficients in the model systems and scenarios of the preceding section.

Model system Steady-State 1 (SS1) demonstrates the coupling of gas-surface transport (adsorption), surface-bulk transport (solvation), and chemical reaction at the surface, and the application of effective adsorption equilibrium constants, which are expected to be relevant in particular for highly reactive trace gas species and highly viscous or solid particles. Model system Steady-State 2 (SS2) illustrates the interaction of multiple competitively adsorbing species at the surface. Model system Steady-State 3 and 4 (SS3 and
SS4) show differences between trace gas reactions at the surface following Langmuir-Hinshelwood and Eley-Rideal mechanisms, respectively. Model systems Steady-State 5 and 6 (SS5 and SS6) illustrate effects of reversible adsorption on gas uptake, which is purely solubility-driven (only gassurface and surface-bulk transport, no chemical reactions).

3.1 Model system Steady-State 1 (SS1): adsorption, surface layer reaction with particle components, and surface-bulk transport

In model system SS1, we consider a trace gas $\mathrm{X}_{1}$, which undergoes reversible adsorption (gas-surface transport), surface-bulk transport, and a surface layer reaction $\left(\mathrm{SLR} 1: \mathrm{X}_{1}(\mathrm{~s})+\mathrm{Y}_{1}(\mathrm{~s}) \rightarrow\right.$ products) under (quasi-)steady-state conditions. In this case the PRA adsorption-reaction steadystate equations (PRA Sect. 4.5.1, Special Case B) for the effective Langmuir adsorption equilibrium constant $K_{\text {ads, X1 }}^{\prime}$, pseudo-first-order surface reaction rate coefficient $k_{\mathrm{s}, \mathrm{X} 1}$, sorption layer surface coverage $\theta_{\mathrm{s}}$, surface accommodation coefficient $\alpha_{\mathrm{s}, \mathrm{X} 1}$, bulk accommodation coefficient $\alpha_{\mathrm{b}, \mathrm{X} 1}$, and uptake coefficient $\gamma_{\mathrm{X} 1}$ can be reduced to:

$$
\begin{aligned}
& K_{\mathrm{ads}, \mathrm{X} 1}^{\prime}=\alpha_{\mathrm{s}, 0, \mathrm{X} 1} \frac{\sigma_{\mathrm{X} 1} \omega_{\mathrm{X} 1}}{4\left(k_{\mathrm{d}, \mathrm{X} 1}+k_{\mathrm{s}, \mathrm{X} 1}+k_{\mathrm{s}, \mathrm{b}, \mathrm{net}, \mathrm{X} 1}\right)} \\
& k_{\mathrm{s}, \mathrm{X} 1}=k_{\mathrm{SLR} 1, \mathrm{X} 1, \mathrm{Y} 1}\left[\mathrm{Y}_{1}\right]_{\mathrm{ss}} \\
& \theta_{S}=\frac{K_{\mathrm{ads}, \mathrm{X} 1}^{\prime}\left[\mathrm{X}_{1}\right]_{\mathrm{gs}}}{1+K_{\mathrm{ads}, \mathrm{X} 1}^{\prime}\left[\mathrm{X}_{1}\right]_{\mathrm{gs}}} \\
& \alpha_{\mathrm{s}, \mathrm{X} 1}=\alpha_{\mathrm{s}, 0, \mathrm{X} 1}\left(1-\theta_{\mathrm{s}}\right)=\frac{\alpha_{\mathrm{s}, 0, \mathrm{X} 1}}{1+K_{\mathrm{ads}, \mathrm{X} 1}^{\prime}\left[\mathrm{X}_{1}\right]_{\mathrm{gs}}} \\
& \alpha_{\mathrm{b}, \mathrm{X} 1}=\alpha_{\mathrm{s}, \mathrm{X} 1} \frac{k_{\mathrm{s}, \mathrm{b}, \mathrm{X} 1}}{k_{\mathrm{s}, \mathrm{b}, \mathrm{X} 1}+k_{\mathrm{s}, \mathrm{X} 1}+k_{\mathrm{d}, \mathrm{X} 1}} \\
& \gamma_{\mathrm{X} 1}=\gamma_{\mathrm{sor}, \mathrm{X} 1}=\alpha_{\mathrm{s}, \mathrm{X} 1} \frac{k_{\mathrm{s}, \mathrm{X} 1}+k_{\mathrm{s}, \mathrm{b}, \mathrm{net}, \mathrm{X} 1}}{k_{\mathrm{s}, \mathrm{b}, \mathrm{net}, \mathrm{X} 1}+k_{\mathrm{s}, \mathrm{X} 1}+k_{\mathrm{d}, \mathrm{X} 1}}
\end{aligned}
$$

For the exemplary model simulations illustrated in Fig. 10, the following input parameters have been used: $\quad \alpha_{\mathrm{s}, 0, \mathrm{X} 1}=10^{-3} ; \quad \omega_{\mathrm{X} 1}=3.6 \times 10^{4} \mathrm{~cm} \mathrm{~s}^{-1} ; \tau_{\mathrm{X} 1}=18 \mathrm{~s}$ and $k_{\mathrm{d}, \mathrm{X} 1}=5.6 \times 10^{-2} \mathrm{~s}^{-1} ; \quad \sigma_{\mathrm{X} 1}=1.8 \times 10^{-15} \mathrm{~cm}^{2}$; $k_{\mathrm{SLR} 1, \mathrm{X} 1, \mathrm{Y} 1}=2 \times 10^{-17} \quad \mathrm{~cm}^{2} \quad \mathrm{~s}^{-1} ; \quad\left[\mathrm{Y}_{1}\right]_{\mathrm{ss}}=1 \times 10^{14} \mathrm{~cm}^{-2}$. $k_{\mathrm{s}, \mathrm{b}, \text { net,X1 }}$ was set equal to zero (scenario SS1-1), to $k_{\mathrm{s}, \mathrm{X} 1}$ (SS1-2), to $k_{\mathrm{d}, \mathrm{X} 1}$ (SS1-3), and to multiples of $10^{2}$ and $10^{4}$

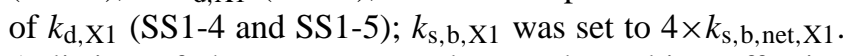
A listing of the parameter values and resulting effective adsorption equilibrium constants $K_{\mathrm{ads}, \mathrm{X} 1}^{\prime}$ is given in Table 2 . $\left[\mathrm{X}_{1}\right]_{\mathrm{gs}}$ was varied from $10^{9} \mathrm{~cm}^{-3}$ to $10^{15} \mathrm{~cm}^{-3}$, corresponding to volume mixing ratios of about $100 \mathrm{ppt}$ to $100 \mathrm{ppm}$ at ambient temperature and pressure.

$\omega_{\mathrm{X} 1}, \alpha_{\mathrm{s}, 0, \mathrm{X} 1}, \tau_{\mathrm{X} 1}, \sigma_{\mathrm{X} 1}$, and $k_{\mathrm{SLR} 1, \mathrm{X} 1, \mathrm{Y} 1}$ are based on the values reported by Pöschl et al. (2001) for the interaction of ozone with the polycyclic aromatic hydrocarbon 

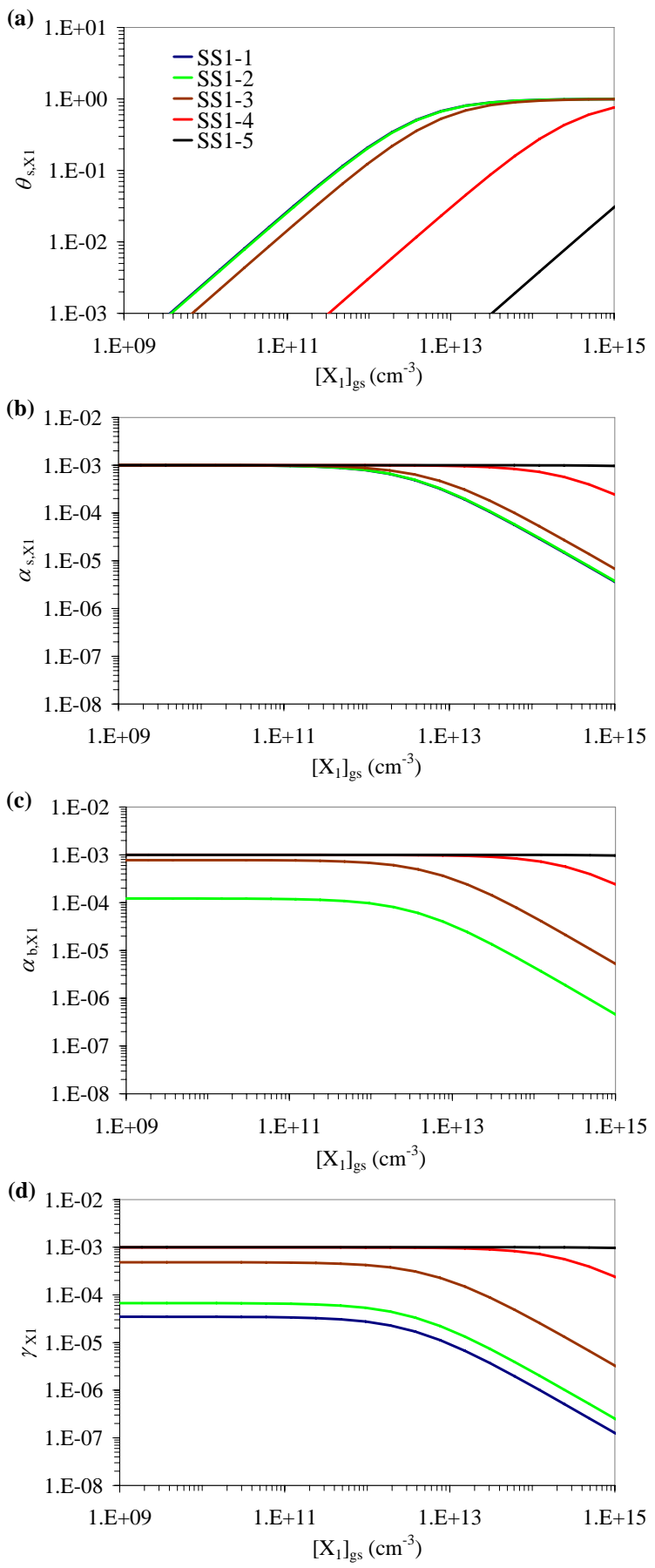

Fig. 10. Exemplary numerical simulations for model system Steady-State 1 (SS1), describing adsorption, surface layer reaction with a particle component, and surface-bulk transport of a trace gas $\mathrm{X}_{1}$ : sorption layer surface coverage $\theta_{\mathrm{s}}(\mathbf{a})$, surface accommodation coefficient $\alpha_{\mathrm{s}, \mathrm{X} 1}(\mathbf{b})$, and bulk accommodation coefficient $\alpha_{\mathrm{b}, \mathrm{X} 1}$ (c), and uptake coefficient $\gamma_{\mathrm{X} 1}$ (d) as a function of near-surface gas phase concentration $\left[\mathrm{X}_{1}\right]_{\mathrm{gs}}$ for scenarios SS1-1 (blue), SS1-2 (green), SS1-3 (yellow), SS1-4 (red), and SS1-5 (black) as defined in Table 2.
Table 2. Scenarios, rate parameters, and adsorption equilibrium constant for model system SS1 describing adsorption, surface layer reaction with particle components, and surface-bulk transport under steady state conditions. $k_{\mathrm{s}, \mathrm{b}, \mathrm{X} 1}$ is the first-order rate coefficient

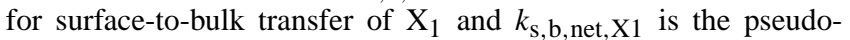
first-order rate coefficient for the net surface-to-bulk transfer of $X_{1}$. $K_{\mathrm{ads}, \mathrm{X} 1}^{\prime}$ is the effective adsorption equilibrium constant of $\mathrm{X}_{1}$.

\begin{tabular}{llll}
\hline Scenario & $\begin{array}{l}k_{\mathrm{s}, \mathrm{b}, \text { net, } \mathrm{X} 1} \\
\left(\mathrm{~s}^{-1}\right)\end{array}$ & $\begin{array}{l}k_{\mathrm{s}, \mathrm{b}, \mathrm{X} 1} \\
\left(\mathrm{~s}^{-1}\right)\end{array}$ & $\begin{array}{l}K_{\mathrm{ads}, \mathrm{X} 1}^{\prime} \\
\left(\mathrm{cm}^{3}\right)\end{array}$ \\
\hline SS1-1 & 0 & 0 & $2.7 \times 10^{-13}$ \\
SS1-2 & $2 \times 10^{-3}$ & $8 \times 10^{-3}$ & $2.6 \times 10^{-13}$ \\
SS1-3 & $5 \times 10^{-2}$ & $2 \times 10^{-1}$ & $1.5 \times 10^{-13}$ \\
SS1-4 & $5 \times 10^{0}$ & $2 \times 10^{1}$ & $3.1 \times 10^{-15}$ \\
SS1-5 & $5 \times 10^{2}$ & $2 \times 10^{3}$ & $3.1 \times 10^{-17}$ \\
\hline
\end{tabular}

benzo[a]pyrene on soot. The other values have been chosen to illustrate characteristic parameter dependencies and the differences between systems dominated by surface processes (SS1-1, solid particles), influenced by surface and bulk processes (SS1-2 to SS1-4; liquid particles with high viscosity and/or high surface reactivity), or dominated by bulk processes (SS1-5; liquid particles with low viscosity and/or low surface reactivity).

Figure 10a-d displays $\theta_{\mathrm{s}}, \alpha_{\mathrm{s}, \mathrm{X} 1}, \alpha_{\mathrm{b}, \mathrm{X} 1}$, and $\gamma_{\mathrm{X} 1}$ as a function of gas phase concentration for the five scenarios SS1-1 to SS1-5 with different (net) surface-to-bulk mass transport rate coefficients and effective adsorption equilibrium constants (Table 2). In all scenarios $\theta_{\mathrm{s}, \mathrm{X} 1}$ increases near-linearly with $\left[\mathrm{X}_{1}\right]_{\mathrm{gs}}$ while $\alpha_{\mathrm{s}, \mathrm{X} 1}, \alpha_{\mathrm{b}, \mathrm{X} 1}$, and $\gamma_{\mathrm{X} 1}$ are independent of $\left[\mathrm{X}_{1}\right]_{\mathrm{gs}}$ as long as $\left[\mathrm{X}_{1}\right]_{\mathrm{gs}} \ll 1 / K_{\mathrm{ads}, \mathrm{X} 1}^{\prime}$. At $\left[\mathrm{X}_{1}\right]_{\mathrm{gs}} \approx 1 / K_{\mathrm{ads}, \mathrm{X} 1}^{\prime}$ the effects of reversible and competitive adsorption inhibit the increase of $\theta_{\mathrm{s}}$ with $\left[\mathrm{X}_{1}\right]_{\mathrm{gs}}$ (characteristic shape of Langmuir isotherm), and induce a decrease of $\alpha_{\mathrm{s}, \mathrm{X} 1}, \alpha_{\mathrm{b}, \mathrm{X} 1}$, and $\gamma \mathrm{X} 1$ with $\left[\mathrm{X}_{1}\right]_{\mathrm{gs}}$. At $\left[\mathrm{X}_{1}\right]_{\mathrm{gs}} \gg 1 / K_{\mathrm{ads}, \mathrm{X} 1}^{\prime}$ the sorption layer surface coverage approaches unity, leading to a steep decrease of $\alpha_{\mathrm{s}, \mathrm{X} 1}, \alpha_{\mathrm{b}, \mathrm{X} 1}$, and $\gamma_{\mathrm{X} 1}$ with $\left[\mathrm{X}_{1}\right]_{\mathrm{gs}}$ (near-constant fluxes of surface layer reaction and surface-to-bulk transport vs. linear increase of gas kinetic flux to the surface).

Scenario SS1-1 (blue lines in Fig. 10a-d) corresponds to a simple Langmuir-Hinshelwood-type reaction mechanism, as discussed in model systems S1-S3 and by Ammann et al. (2003). It exhibits the strongest gas phase concentration dependency, the earliest onset of surface saturation and reduction of $\alpha_{\mathrm{s}, \mathrm{X} 1}$, the lowest values of $\gamma_{\mathrm{X} 1}$, and $\alpha_{\mathrm{b}, \mathrm{X} 1}=0$. In scenarios SS1-2 to SS1-4 the increase of $k_{\mathrm{s}, \mathrm{b}, \mathrm{X} 1}$ and $k_{\mathrm{s}, \mathrm{b}, \text { net,X1 }}$ and the decrease of $K_{\mathrm{ads}, \mathrm{X} 1}^{\prime}$, respectively, move the onset of surface saturation towards higher $\left[\mathrm{X}_{1}\right]_{\mathrm{gs}}$, and the values of $\alpha_{\mathrm{b}, \mathrm{X} 1}$ and $\gamma_{\mathrm{X} 1}$ approach $\alpha_{\mathrm{s}, \mathrm{X} 1}$ as an upper limit. In scenario SS1-5 (black lines in Fig. 10a-d) the sorption layer surface coverage remains far below unity even at high gas phase concentration, and $\alpha_{\mathrm{s}, \mathrm{X} 1}=\alpha_{\mathrm{b}, \mathrm{X} 1}=\gamma_{\mathrm{X} 1}$ are independent 

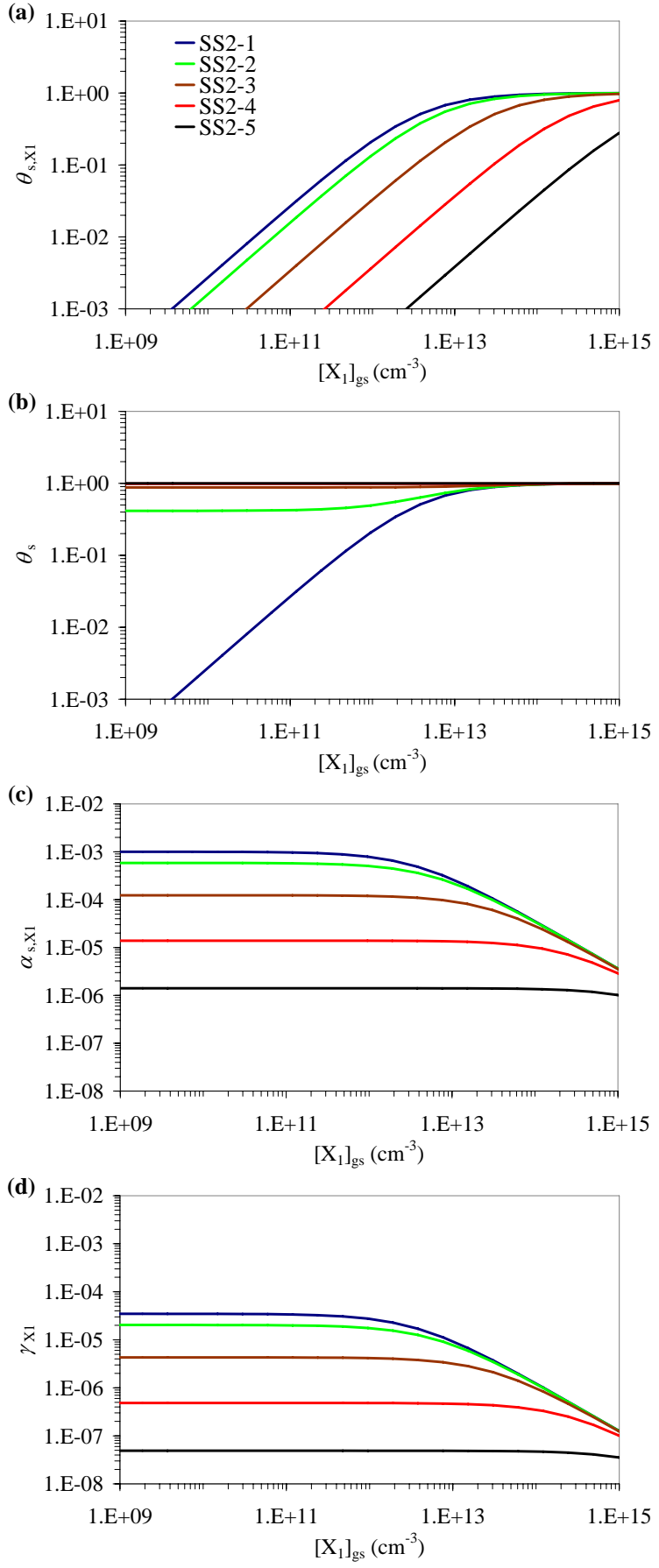

Fig. 11. Exemplary numerical simulations for model system Steady-State 2 (SS2), describing competitive co-adsorption of trace gases $X_{1}$ and $X_{2}$, and a surface layer reaction of $X_{1}$ with a particle component: fractional surface coverage $\theta_{\mathrm{s}, \mathrm{X} 1}$ (a), total sorption layer surface coverage $\theta_{\mathrm{s}}$ (b), surface accommodation coefficient $\alpha_{\mathrm{s}, \mathrm{X} 1}$ (c), and uptake coefficient $\gamma_{\mathrm{X} 1}$ (d) as a function of near-surface gas phase concentration $\left[\mathrm{X}_{1}\right]_{\mathrm{gs}}$ for scenarios SS2-1 ([X $\left.]_{2}\right]_{g s}=0$, blue, identical with SS1-1 in Fig. 10 and Table 2), SS2-2 ([X $]_{\mathrm{gs}}=2.5 \times 10^{12} \mathrm{~cm}^{-3}$, green $), \mathrm{SS} 2-3$ $\left(\left[\mathrm{X}_{2}\right]_{\mathrm{gs}}=2.5 \times 10^{13} \mathrm{~cm}^{-3}\right.$ yellow $), \mathrm{SS} 2-4\left(\left[\mathrm{X}_{2}\right]_{\mathrm{gs}}=2.5 \times 10^{14} \mathrm{~cm}^{-3}\right.$, red), and SS2-5 $\left(\left[\mathrm{X}_{2}\right]_{\mathrm{gs}}=2.5 \times 10^{15} \mathrm{~cm}^{-3}\right.$, black $)$. of $\left[\mathrm{X}_{1}\right]_{\mathrm{gs}}$. Under these conditions the gas-particle interactions are dominated by bulk processes, and the bulk accommodation coefficient convoluting surface accommodation and surface-bulk transport is suitable to describe the overall gas uptake.

3.2 Model system Steady-State 2 (SS2): competitive coadsorption and surface layer reaction with particle components

Model system SS2 is analogous to SS1, except that no surface-bulk transport of $\mathrm{X}_{1}$ is considered here. Instead, a second trace gas $\mathrm{X}_{2}$ competitively co-adsorbs to the surface. $\mathrm{X}_{2}$ is assumed to be non-reactive, and to undergo no surfacebulk transport either. In this case the PRA adsorptionreaction steady-state equations (PRA Sect. 4.5.1, Special Case B) can be reduced to:

$$
\begin{aligned}
& K_{\mathrm{ads}, \mathrm{X} 1}^{\prime}=\alpha_{\mathrm{s}, 0, \mathrm{X} 1} \frac{\sigma_{\mathrm{X} 1} \omega_{\mathrm{X} 1}}{4\left(k_{\mathrm{d}, \mathrm{X} 1}+k_{\mathrm{s}, \mathrm{X} 1}\right)} \\
& K_{\mathrm{ads}, \mathrm{X} 2}^{\prime}=\alpha_{\mathrm{s}, 0, \mathrm{X} 2} \frac{\sigma_{\mathrm{X} 2} \omega_{\mathrm{X} 2}}{4 k_{\mathrm{d}, \mathrm{X} 2}} \\
& \theta_{\mathrm{s}, \mathrm{X} 1}=\frac{K_{\mathrm{ads}, \mathrm{X} 1}^{\prime}\left[\mathrm{X}_{1}\right]_{\mathrm{gs}}}{1+K_{\mathrm{ads}, \mathrm{X} 1}^{\prime}\left[\mathrm{X}_{1}\right]_{\mathrm{gs}}+K_{\mathrm{ads}, \mathrm{X} 2}^{\prime}\left[\mathrm{X}_{2}\right]_{\mathrm{gs}}} \\
& \theta_{s}=\frac{K_{\mathrm{ads}, \mathrm{X} 1}^{\prime}\left[\mathrm{X}_{1}\right]_{\mathrm{gs}}+K_{\mathrm{ads}, \mathrm{X} 2}^{\prime}\left[\mathrm{X}_{2}\right]_{\mathrm{gs}}}{1+K_{\mathrm{ads}, \mathrm{X} 1}^{\prime}\left[\mathrm{X}_{1}\right]_{\mathrm{gs}}+K_{\mathrm{ads}, \mathrm{X} 2}^{\prime}\left[\mathrm{X}_{2}\right]_{\mathrm{gs}}} \\
& \alpha_{\mathrm{s}, \mathrm{X} 1}=\frac{\alpha_{\mathrm{s}, 0, \mathrm{X} 1}}{1+K_{\mathrm{ads}, \mathrm{X} 1}^{\prime}\left[\mathrm{X}_{1}\right]_{\mathrm{gs}}+K_{\mathrm{ads}, \mathrm{X} 2}^{\prime}\left[\mathrm{X}_{2}\right]_{\mathrm{gs}}} \\
& k_{\mathrm{s}, \mathrm{X} 1}=k_{\mathrm{SLR} 1, \mathrm{X} 1, \mathrm{Y} 1\left[\mathrm{Y}_{1}\right]_{\mathrm{ss}}} \\
& \gamma_{\mathrm{X} 1}=\gamma_{\mathrm{sor}, \mathrm{X} 1}=\alpha_{\mathrm{s}, \mathrm{X} 1} \frac{k_{\mathrm{s}, \mathrm{X} 1}}{k_{\mathrm{d}, \mathrm{X} 1}}
\end{aligned}
$$

$\theta_{\mathrm{s}, \mathrm{X} 1}$ represents the fractional surface coverage of $\mathrm{X}_{1}$ $\left(\theta_{\mathrm{s}, \mathrm{X} 1}=\sigma_{\mathrm{X} 1}\left[\mathrm{X}_{1}\right]_{\mathrm{s}}\right)$, whereas $\theta_{\mathrm{S}}$ is the total sorption layer surface coverage $\left(\theta_{\mathrm{s}}=\sigma_{\mathrm{X} 1}\left[\mathrm{X}_{1}\right]_{\mathrm{s}}+\sigma_{\mathrm{X} 2}\left[\mathrm{X}_{2}\right]_{\mathrm{s}}\right)$. For the exemplary model simulations based on Eqs. (33)-(39) and illustrated in Fig. 11, the input parameters for $X_{1}$ have been the same as in scenario SS1-1 $\left(K_{\mathrm{ads}, \mathrm{X} 1}^{\prime}=2.7 \times 10^{-13} \mathrm{~cm}^{3}\right)$. Except for its non-reactivity, $\mathrm{X}_{2}$ was assumed to have the same properties as $\mathrm{X}_{1}\left(K_{\mathrm{ads}, \mathrm{X} 2}=K_{\mathrm{ads}, \mathrm{X} 2}^{\prime}=2.8 \times 10^{-13} \mathrm{~cm}^{3}\right)$. In scenarios SS2-1 to SS2-5 the gas phase concentration of $\mathrm{X}_{2},\left[\mathrm{X}_{2}\right]_{\mathrm{gs}}$, was set to $0,2.5 \times 10^{12} \mathrm{~cm}^{3}, 2.5 \times 10^{13} \mathrm{~cm}^{3}, 2.5 \times 10^{14} \mathrm{~cm}^{3}$, or $2.5 \times 10^{15} \mathrm{~cm}^{3}$, respectively (corresponding to about $0.1-$ $100 \mathrm{ppm}$ at ambient temperature and pressure).

Figure $11 \mathrm{a}-\mathrm{d}$ displays $\theta_{\mathrm{s}}, \theta_{\mathrm{s}, \mathrm{X} 1}, \alpha_{\mathrm{s}, \mathrm{X} 1}$, and $\gamma_{\mathrm{X} 1}$ as a function of gas phase concentration for the five scenarios SS21 to SS2-5. In all scenarios $\theta_{\mathrm{S}, \mathrm{X} 1}$ increases near-linearly with $\left[\mathrm{X}_{1}\right]_{\mathrm{gs}}$ while $\alpha_{\mathrm{s}, \mathrm{X} 1}$ and $\gamma_{\mathrm{X} 1}$ are independent of $\left[\mathrm{X}_{1}\right]_{\mathrm{gs}}$ as long as $\left[\mathrm{X}_{1}\right]_{\mathrm{gs}} \ll 1 / K_{\mathrm{ads}, \mathrm{X} 1}^{\prime}+\left[\mathrm{X}_{2}\right]_{\mathrm{gs}} K_{\mathrm{ads}, \mathrm{X} 2}^{\prime} / K_{\mathrm{X} 1}^{\prime}\left(\theta_{\mathrm{s}, \mathrm{X} 1} \ll 1\right)$. At $\left[\mathrm{X}_{1}\right]_{\mathrm{gs}} \approx 1 / K_{\mathrm{ads}, \mathrm{X} 1}^{\prime}+\left[\mathrm{X}_{2}\right]_{\mathrm{gs}} K_{\mathrm{ads}, \mathrm{X} 2}^{\prime} / K_{\mathrm{ads}, \mathrm{X} 1}^{\prime}$, the effects of 
reversible and competitive adsorption of $\mathrm{X}_{1}$ inhibit the further increase of $\theta_{\mathrm{s}, \mathrm{X} 1}$ with $\left[\mathrm{X}_{1}\right]_{\mathrm{gs}}$ (characteristic shape of Langmuir isotherm), and induce a decrease of $\alpha_{\mathrm{s}, \mathrm{X} 1}$ and $\gamma_{\mathrm{X} 1}$ with $\left[\mathrm{X}_{1}\right]_{\mathrm{gs}}$. At $\left[\mathrm{X}_{1}\right]_{\mathrm{gs}} \gg 1 / K_{\mathrm{ads}, \mathrm{X} 1}^{\prime}+\left[\mathrm{X}_{2}\right]_{\mathrm{gs}} K_{\mathrm{ads}, \mathrm{X} 2}^{\prime} / K_{\mathrm{ads}, \mathrm{X} 1}^{\prime}$, the fractional surface coverage by $\mathrm{X}_{1}$ approaches unity, leading to a steep decrease of $\alpha_{\mathrm{s}, \mathrm{X} 1}$ and $\gamma_{\mathrm{X} 1}$ with $\left[\mathrm{X}_{1}\right]_{\mathrm{gs}}$ (nearconstant flux of surface layer reaction vs. linear increase of gas kinetic flux to the surface).

Scenario SS2-1 (blue lines in Fig. 11a-d; $\left[\mathrm{X}_{2}\right]_{\mathrm{gs}}=0$ ) is identical with scenario SS1-1 (Fig. 10) and exhibits the same features as discussed in Sect. 3.1. In scenarios SS1-2 to SS1-5 the increase of $\left[\mathrm{X}_{2}\right]_{\mathrm{gs}}$ enhances the total sorption layer coverage, $\theta_{\mathrm{s}}$, and and significantly decreases $\alpha_{\mathrm{s}, \mathrm{X} 1}, \theta_{\mathrm{s}, \mathrm{X} 1}$, and $\gamma_{\mathrm{X} 1}$ for $\mathrm{X}_{1}$ gas phase concentrations up to $\left[\mathrm{X}_{1}\right]_{\mathrm{gs}} \approx 1 / K_{\mathrm{ads}, \mathrm{X} 1}^{\prime}+\left[\mathrm{X}_{2}\right]_{\mathrm{gs}} K_{\mathrm{ads}, \mathrm{X} 2}^{\prime} / K_{\mathrm{ads}, \mathrm{X} 1}^{\prime}$. At $\left[\mathrm{X}_{1}\right]_{\mathrm{gs}} \ll 1 / K_{\mathrm{ads}, \mathrm{X} 1}^{\prime}+\left[\mathrm{X}_{2}\right]_{\mathrm{gs}} K_{\mathrm{ads}, \mathrm{X} 2}^{\prime} / K_{\mathrm{ads}, \mathrm{X} 1}^{\prime}$, the values of $\alpha_{\mathrm{s}, \mathrm{X} 1}$ and $\gamma_{\mathrm{X} 1}$ become independent of $\left[\mathrm{X}_{2}\right]_{\mathrm{gs}}\left(\theta_{\mathrm{s}}\right.$ dominated by $\mathrm{X}_{1}$ ).

The outlined effects of competitive co-adsorption are consistent with the experimental data reported by Pöschl et al. (2001) for $\mathrm{H}_{2} \mathrm{O}$ and $\mathrm{O}_{3}$ interacting with soot aerosol particles $\left(K_{\text {ads, } \mathrm{H} 2 \mathrm{O}}^{\prime} \ll K_{\text {ads, } \mathrm{O} 3}^{\prime}\right)$, and more recent observations for $\mathrm{NO}_{2}$ and $\mathrm{O}_{3}\left(K_{\text {ads, } \mathrm{NO} 2}^{\prime} \approx K_{\text {ads, }}^{\prime}\right.$; publication of measurement data in preparation; preliminary results reported by Pöschl, 2002, and Schauer et al., 2004).

3.3 Model system Steady-State 3 (SS3): competitive coadsorption and surface layer self-reaction of adsorbate molecules (Langmuir-Hinshelwood mechanism)

Model system SS3 is analogous to SS2, except that $\mathrm{X}_{1}$ undergoes self-reaction rather than reaction with quasi-static surface components. The self-reaction of $\mathrm{X}_{1}$ is assumed to proceed exclusively via a surface layer reaction (LangmuirHinshelwood mechanism; SLR1: $\mathrm{X}_{1}(\mathrm{~s})+\mathrm{X}_{1}(\mathrm{~s}) \rightarrow$ products). The reaction products are assumed to be non-reactive and to have very low effective adsorption equilibrium constants, i.e. negligible influence on the surface concentrations of $X_{1}$ and $\mathrm{X}_{2}$ and on the total sorption layer coverage. The overall process can be viewed as heterogeneous catalysis of $\mathrm{X}_{1}$ decomposition by self-reaction. In this case the same set of equations as in model system SS2 are applicable, except that the pseudo-first-order surface reaction rate coefficient is given by

$k_{\mathrm{s}, \mathrm{X} 1}=k_{\mathrm{SLR} 1, \mathrm{X} 1, \mathrm{X} 1}\left[\mathrm{X}_{1}\right]_{\mathrm{s}}$

For the exemplary model simulations illustrated in Fig. 12, the input parameters for $X_{1}$ and $X_{2}$ have been the same as in scenarios SS1-1 and SS2-1, except the replacement of $k_{\mathrm{SLR} 1, \mathrm{X} 1, \mathrm{Y} 1}$ by the surface layer self-reaction rate coefficient $k_{\mathrm{SLR} 1, \mathrm{X} 1, \mathrm{X} 1}=2 \times 10^{-17} \mathrm{~cm}^{2} \mathrm{~s}^{-1}$. In scenarios SS3-1 to $\mathrm{SS} 3-5$, the gas phase concentration of $\mathrm{X}_{2},\left[\mathrm{X}_{2}\right]_{\mathrm{gs}}$, was again set to $0,2.5 \times 10^{12} \mathrm{~cm}^{3}, 2.5 \times 10^{13} \mathrm{~cm}^{3}, 2.5 \times 10^{14} \mathrm{~cm}^{3}$, or $2.5 \times 10^{15} \mathrm{~cm}^{3}$, respectively.

Figure 12a-d displays $\theta_{\mathrm{s}, \mathrm{X} 1}, \theta_{\mathrm{s}}, \alpha_{\mathrm{s}, \mathrm{X} 1}$, and $\gamma_{\mathrm{X} 1}$ as a function of gas phase concentration for the five scenar-
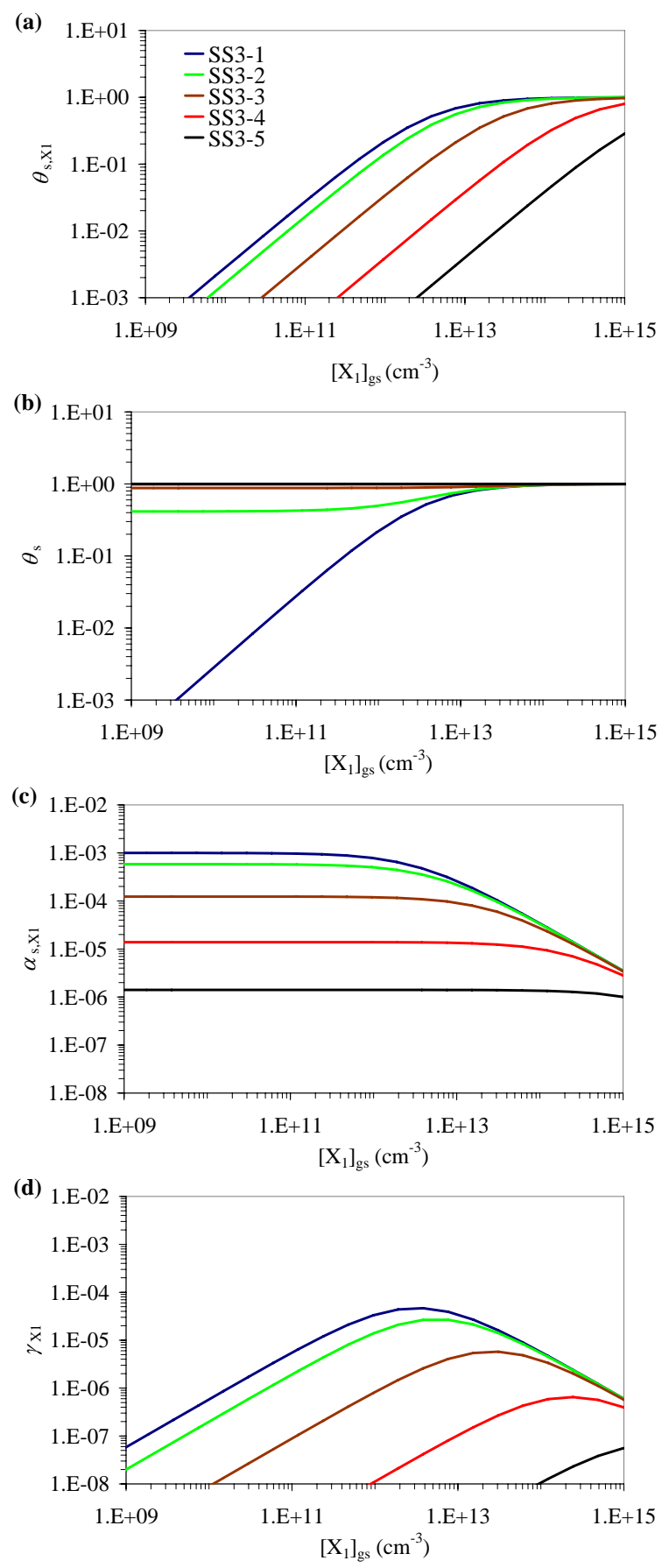

Fig. 12. Exemplary numerical simulations for model system Steady-State 3 (SS3), describing competitive co-adsorption of trace gases $X_{1}$ and $X_{2}$, and surface layer self-reaction of $X_{1}$ : fractional surface coverage $\theta_{\mathrm{s}, \mathrm{X} 1}(\mathbf{a})$, total sorption layer surface coverage $\theta_{\mathrm{s}}$ (b), surface accommodation coefficient $\alpha_{\mathrm{s}, \mathrm{X} 1}$ (c), and uptake coefficient $\gamma_{\mathrm{X} 1}$ (d) as a function of near-surface gas phase concentration $\left[\mathrm{X}_{1}\right]_{\mathrm{gs}}$ for scenarios SS3-1 ([X $]_{\mathrm{gs}}=0$, blue, identical with SS1-1 in Fig. 10 and Table 2), SS3-2 ([X $]_{\mathrm{gs}}=2.5 \times 10^{12} \mathrm{~cm}^{-3}$, green $), \mathrm{SS} 3-3$ $\left(\left[\mathrm{X}_{2}\right]_{\mathrm{gs}}=2.5 \times 10^{13} \mathrm{~cm}^{-3}\right.$ yellow $), \mathrm{SS} 3-4\left(\left[\mathrm{X}_{2}\right]_{\mathrm{gs}}=2.5 \times 10^{14} \mathrm{~cm}^{-3}\right.$, red), and SS3-5 $\left(\left[\mathrm{X}_{2}\right]_{\mathrm{gs}}=2.5 \times 10^{15} \mathrm{~cm}^{-3}\right.$, black $)$. 
ios SS3-1 to SS3-5. In all scenarios, $\theta_{\mathrm{S}, \mathrm{X} 1}$ and $\gamma_{\mathrm{X} 1}$ increase near-linearly with $\left[\mathrm{X}_{1}\right]_{\mathrm{gs}}$ while $\alpha_{\mathrm{s}, \mathrm{X} 1}$ is independent of $\left[\mathrm{X}_{1}\right]_{\mathrm{gs}}$ as long as $\left[\mathrm{X}_{1}\right]_{\mathrm{gs}} \ll 1 / K_{\mathrm{ads}, \mathrm{X} 1}^{\prime}+\left[\mathrm{X}_{2}\right]_{\mathrm{gs}} K_{\mathrm{ads}, \mathrm{X} 2}^{\prime} / K_{\mathrm{ads}, \mathrm{X} 1}^{\prime}$ $\left(\theta_{\mathrm{s}, \mathrm{X} 1} \ll 1\right)$. At $\left[\mathrm{X}_{1}\right]_{\mathrm{gs}} \approx 1 / K_{\mathrm{ads}, \mathrm{X} 1}^{\prime}+\left[\mathrm{X}_{2}\right]_{\mathrm{gs}} K_{\mathrm{ads}, \mathrm{X} 2}^{\prime} / K_{\mathrm{ads}, \mathrm{X} 1}^{\prime}$, the effects of reversible and competitive adsorption of $\mathrm{X}_{1}$ inhibit the further increase of $\theta_{\mathrm{s}, \mathrm{X} 1}$ with $\left[\mathrm{X}_{1}\right]_{\mathrm{gs}}$ (characteristic shape of Langmuir isotherm), and lead to a decrease of $\alpha_{\mathrm{s}, \mathrm{X} 1}$ and to a maximum of $\gamma_{\mathrm{X} 1}$ (maximum ratio between the fluxes of surface reaction and surface collisions). At $\left[\mathrm{X}_{1}\right]_{\mathrm{gs}} \ll 1 / K_{\text {ads, } \mathrm{X} 1}^{\prime}+\left[\mathrm{X}_{2}\right]_{\mathrm{gs}} K_{\text {ads. } \mathrm{X} 2}^{\prime} / K_{\text {ads }, \mathrm{X} 1}^{\prime}$ the fractional surface coverage by $\mathrm{X}_{1}$ approaches unity, leading to a steep decrease of $\alpha_{\mathrm{s}, \mathrm{X} 1}$ and $\gamma_{\mathrm{X} 1}$ with $\left[\mathrm{X}_{1}\right]_{\mathrm{gs}}$ (near-constant flux of surface layer self-reaction vs. linear increase of gas kinetic flux to the surface).

The main feature differentiating SS3 from SS2 is the increase of $\gamma_{\mathrm{X} 1}$ with increasing $\left[\mathrm{X}_{1}\right]_{\mathrm{gs}}$ at low concentration levels, which is due to the increasing rate of surface layer selfreaction with increasing surface coverage by $\mathrm{X}_{1}$ (secondorder dependence on $\left[\mathrm{X}_{1}\right]_{\mathrm{gs}}$ ). At high concentration levels the surface is saturated with $\mathrm{X}_{1}$, and $\alpha_{\mathrm{s}, \mathrm{X} 1}$ as well as $\gamma_{\mathrm{X} 1}$ decrease with further increasing $\left[X_{1}\right]_{\mathrm{gs}}$ in analogy to model system SS2 and SS1 (Figs. 10 and 11).

Scenario SS3-1 (blue lines in Fig. 12a-d, $\left[\mathrm{X}_{2}\right]_{\mathrm{gs}}=0$ ) exhibits the highest values of $\theta_{\mathrm{s}, \mathrm{X} 1}, \alpha_{\mathrm{s}, \mathrm{X} 1}$, and $\gamma_{\mathrm{X} 1}$ and the lowest values of $\theta_{\mathrm{s}}$. In scenarios SS32 to SS3-5 the increase of $\left[\mathrm{X}_{2}\right]_{\mathrm{gs}}$ enhances the total sorption layer coverage, $\theta_{\mathrm{s}}$, and significantly decreases $\alpha_{\mathrm{s}, \mathrm{X} 1}, \theta_{\mathrm{s}, \mathrm{X} 1}$, and $\gamma_{\mathrm{X} 1}$ for $\mathrm{X}_{1}$ gas phase concentrations up to $\left[\mathrm{X}_{1}\right]_{\mathrm{gs}} \approx 1 / K_{\text {ads, } \mathrm{X} 1}^{\prime}+\left[\mathrm{X}_{2}\right]_{\mathrm{gs}} K_{\text {ads }, \mathrm{X} 2}^{\prime} / K_{\text {ads, } \mathrm{X} 1}^{\prime}$. At $\left[\mathrm{X}_{1}\right]_{\mathrm{gs}} \gg 1 / K_{\mathrm{ads}, \mathrm{X} 1}^{\prime}+\left[\mathrm{X}_{2}\right]_{\mathrm{gs}} K_{\mathrm{ads}, \mathrm{X} 2}^{\prime} / K_{\mathrm{ads}, \mathrm{X} 1}^{\prime}$ the values of $\alpha_{\mathrm{S}, \mathrm{X} 1}$ and $\gamma_{\mathrm{X} 1}$ become independent of $\left[\mathrm{X}_{2}\right]_{\mathrm{gs}}\left(\theta_{\mathrm{S}}\right.$ dominated by $\mathrm{X}_{1}$ ). Overall, the effect of $\mathrm{X}_{2}$ in model system SS3 (Fig. 12) is essentially the same as in SS2 (Fig. 11): competitive displacement of $\mathrm{X}_{1}$ in the sorption layer by reversible co-adsorption without interference in chemical reactions.

3.4 Model system Steady-State 4 (SS4): competitive coadsorption and gas-surface self-reaction (Eley-Rideal mechanism)

Model system SS4 is analogous to SS3, except that the surface layer self-reaction of $X_{1}$ is replaced by a gas-surface self-reaction (Eley-Rideal mechanism; GSR1: $\mathrm{X}_{1}(\mathrm{~g})+\mathrm{X}_{1}(\mathrm{~s}) \rightarrow$ products $)$. Again, the overall process can be viewed as heterogeneous catalysis of $\mathrm{X}_{1}$ decomposition by self-reaction, and the same set of equations as in model system SS2 and SS3 are applicable, except that the pseudofirst-order surface reaction rate coefficient and the uptake coefficient are given by

$$
\begin{aligned}
& k_{\mathrm{s}, \mathrm{X} 1}=-\sigma_{\mathrm{X} 1} \gamma_{\mathrm{GSR}, \mathrm{X} 1 \mathrm{X} 1} \frac{\omega_{\mathrm{X} 1}}{4}\left[\mathrm{X}_{1}\right]_{\mathrm{gs}} \\
& \gamma_{\mathrm{X} 1}=\gamma_{\mathrm{sor}, \mathrm{X} 1}+\gamma_{\mathrm{gsr}, \mathrm{X} 1} \\
& \gamma_{\mathrm{sor}, \mathrm{X} 1}=\alpha_{\mathrm{s}, \mathrm{X} 1} \frac{k_{\mathrm{s}, \mathrm{X} 1}}{k_{\mathrm{d}, \mathrm{X} 1}}
\end{aligned}
$$

$\gamma_{\mathrm{gsr}, \mathrm{X} 1}=\gamma_{\mathrm{GSR}, \mathrm{X} 1, \mathrm{X} 1} \theta_{\mathrm{s}, \mathrm{X} 1}$

For the exemplary model simulations illustrated in Fig. 13, the input parameters for $X_{1}$ and $X_{2}$ have been the same as in scenarios SS1-1 to SS3-1, except for the omission of the surface layer reaction rate coefficient and the introduction of the gas-surface self-reaction probability $\gamma_{\mathrm{GSR} 1, \mathrm{X} 1, \mathrm{X} 1}=2 \times 10^{-4}$. In scenarios SS4-1 to SS4-5 the gas phase concentration of $\mathrm{X}_{2},\left[\mathrm{X}_{2}\right]_{\mathrm{gs}}$, was again set to $0,2.5 \times 10^{12} \mathrm{~cm}^{3}, 2.5 \times 10^{13} \mathrm{~cm}^{3}$, $2.5 \times 10^{14} \mathrm{~cm}^{3}$, or $2.5 \times 10^{15} \mathrm{~cm}^{3}$, respectively.

Figure 13a-d displays $\theta_{\mathrm{s}, \mathrm{X} 1}, \theta_{\mathrm{s}}, \alpha_{\mathrm{s}, \mathrm{X} 1}$, and $\gamma_{\mathrm{X} 1}$ as a function of gas phase concentration for the five scenarios SS4-1 to SS4-5. In all scenarios $\theta_{\mathrm{s}, \mathrm{X} 1}$ and $\gamma_{\mathrm{X} 1}$ increase near-linearly with $\left[\mathrm{X}_{1}\right]_{\mathrm{gs}}$, while $\alpha_{\mathrm{s}, \mathrm{X} 1}$ is independent of $\left[\mathrm{X}_{1}\right]_{\mathrm{gs}}$ as long as $\left[\mathrm{X}_{1}\right]_{\mathrm{gs}} \ll 1 / K_{\mathrm{ads}, \mathrm{X} 1}^{\prime}+\left[\mathrm{X}_{2}\right]_{\mathrm{gs}} K_{\mathrm{ads}, \mathrm{X} 2}^{\prime} / K_{\mathrm{ads}, \mathrm{X} 1}^{\prime}\left(\theta_{\mathrm{s}, \mathrm{X} 1} \ll 1\right)$. The increase of $\gamma_{\mathrm{X} 1}$ is similar to that in SS3 and it reflects an effective second-order dependence of the gas uptake on $\left[\mathrm{X}_{1}\right]_{\mathrm{gs}}$, which results from the combination of the (near-)first-order dependencies of the surface concentration $\left[\mathrm{X}_{1}\right]_{\mathrm{s}}$ and of the loss rate coefficient $k_{\mathrm{s}, \mathrm{X} 1}$ on $\left[\mathrm{X}_{1}\right]_{\mathrm{gs}}$.

At $\left[\mathrm{X}_{1}\right]_{\mathrm{gs}} \approx 1 / K_{\mathrm{ads}, \mathrm{X} 1}^{\prime}+\left[\mathrm{X}_{2}\right]_{\mathrm{gs}} K_{\mathrm{ads}, \mathrm{X} 2}^{\prime} / K_{\mathrm{ads}, \mathrm{X} 1}^{\prime}$, the effects of reversible and competitive adsorption of $\mathrm{X}_{1}$ inhibit the further increase of $\theta_{\mathrm{s}, \mathrm{X} 1}$ and $\gamma_{\mathrm{X} 1}$ with $\left[\mathrm{X}_{1}\right]_{\mathrm{gs}}$ (characteristic shape of Langmuir isotherm), and lead to a decrease of $\alpha_{\mathrm{s}, \mathrm{X} 1}$. At $\left[\mathrm{X}_{1}\right]_{\mathrm{gs}} \gg 1 / K_{\mathrm{ads}, \mathrm{X} 1}^{\prime}+\left[\mathrm{X}_{2}\right]_{\mathrm{gs}} K_{\mathrm{ads}, \mathrm{X} 2}^{\prime} / K_{\mathrm{ads}, \mathrm{X} 1}^{\prime}$, the values of $\theta_{\mathrm{s}, \mathrm{X} 1}, \alpha_{\mathrm{s}, \mathrm{X} 1}$ and $\gamma_{\mathrm{X} 1}$ become independent of $\left[\mathrm{X}_{1}\right]_{\mathrm{gs}}$ (near-linear increase of gas-surface reaction flux as well as gas kinetic flux to the surface). Moreover, $\gamma_{\mathrm{X} 1}$ exceeds $\alpha_{\mathrm{s}, \mathrm{X} 1}$ in all scenarios as $\left[\mathrm{X}_{1}\right]_{\mathrm{gs}}$ goes to very high values, i.e. at $\left[\mathrm{X}_{1}\right]_{\mathrm{gs}} \approx 10^{15} \mathrm{~cm}^{-3}$.

The independence of $\alpha_{\mathrm{s}, \mathrm{X} 1}$ and $\gamma_{\mathrm{X} 1}$ from $\left[\mathrm{X}_{1}\right]_{\mathrm{gs}}$ at high gas phase concentration and the fact that the net gas uptake is not limited by surface accommodation, i.e. that $\gamma_{\mathrm{X} 1}$ can exceed $\alpha_{\mathrm{s}, \mathrm{X} 1}$, clearly distinguish SS4 from model systems SS1 to SS3. These fundamental differences are due to the fact that gas-surface reactions are not limited by adsorption and surface saturation but increase with the gas phase concentration and gas kinetic flux to the surface as long as the surface provides reaction partners. In contrast, the surface layer reactions and surface-to-bulk transport, which drive the gas uptake in models systems SS1 to SS3, are fully governed by adsorption and limited by surface saturation.

Scenario SS4-1 (blue lines in Fig. 13a-d, $\left[\mathrm{X}_{2}\right]_{\mathrm{gs}}=0$ ) exhibits the highest values of $\theta_{\mathrm{s}, \mathrm{X} 1}, \alpha_{\mathrm{s}, \mathrm{X} 1}$, and $\gamma_{\mathrm{X} 1}$ and the lowest values of $\theta_{\mathrm{s}}$. In scenarios SS4-2 to SS4-5 the increase of $\left[\mathrm{X}_{2}\right]_{\mathrm{gs}}$ enhances the total sorption layer coverage, $\theta_{\mathrm{s}}$, and significantly decreases $\theta_{\mathrm{s}, \mathrm{X} 1}, \alpha_{\mathrm{s}, \mathrm{X} 1}$, and $\gamma_{\mathrm{X} 1}$ for $\mathrm{X}_{1}$ gas phase concentrations up to $\left[\mathrm{X}_{1}\right]_{\mathrm{gs}} \approx 1 / K_{\mathrm{ads}, \mathrm{X} 1^{+}}{ }^{+}$ $\left[\mathrm{X}_{2}\right]_{\mathrm{gs}} K_{\mathrm{ads}, \mathrm{X} 2}^{\prime} / K_{\mathrm{ads}, \mathrm{X} 1}^{\prime}$. Simlar to model systems SS2 and $\mathrm{SS} 3$, the influence of $\mathrm{X}_{2}$ on of $\theta_{\mathrm{s}, \mathrm{X} 1}, \alpha_{\mathrm{s}, \mathrm{X} 1}$, and $\gamma_{\mathrm{X} 1}$ becomes negligible at $\left[\mathrm{X}_{1}\right]_{\mathrm{gs}} \gg 1 / K_{\mathrm{ads}, \mathrm{X} 1}^{\prime}+\left[\mathrm{X}_{2}\right]_{\mathrm{gs}} \quad K_{\mathrm{ads}, \mathrm{X} 2}^{\prime} / K_{\mathrm{ads}, \mathrm{X} 1}^{\prime}$ in SS4-2 with relatively low gas phase concentration of $\mathrm{X}_{2}\left(\left[\mathrm{X}_{2}\right]_{\mathrm{gs}} \gg 1 / K_{\mathrm{ads}, \mathrm{X} 2}^{\prime}+\left[\mathrm{X}_{1}\right]_{\mathrm{gs}} K_{\mathrm{ads}, \mathrm{X} 1}^{\prime} / K_{\mathrm{ads}, \mathrm{X} 2}^{\prime}\right)$. In contrast to SS2 and SS3, however, the decrease of $\theta_{\mathrm{s}, \mathrm{X} 1}, \quad \alpha_{\mathrm{s}, \mathrm{X} 1}$, and $\gamma_{\mathrm{X} 1}$ by $\mathrm{X}_{2}$ persists in the scenarios 
with relatively high gas phase concentration of $\mathrm{X}_{2}$ $\left(\left[\mathrm{X}_{2}\right]_{\mathrm{gs}} \gg 1 / K_{\mathrm{ads}, \mathrm{X} 2}^{\prime}+\left[\mathrm{X}_{1}\right]_{\mathrm{gs}} K_{\mathrm{ads}, \mathrm{X} 1}^{\prime} / K_{\mathrm{ads}, \mathrm{X} 2}^{\prime} ; \mathrm{SS} 4-3\right.$ to SS4$5)$ even at $\left[\mathrm{X}_{1}\right]_{\mathrm{gs}} \gg 1 / K_{\mathrm{ads}, \mathrm{X} 1}^{\prime}+\left[\mathrm{X}_{2}\right]_{\mathrm{gs}} K_{\mathrm{ads}, \mathrm{X} 2}^{\prime} / K_{\mathrm{ads}, \mathrm{X} 1}^{\prime}$.

Although the role of $X_{2}$ in SS4 (Fig. 13) is in principle the same as SS2 and SS3 (Figs. 11 and 12: enhancement of $\theta_{\mathrm{S}}$ and decrease of $\theta_{\mathrm{s}}$ by competitive displacement of $\mathrm{X}_{1}$ in the sorption layer), the persistence of the influence of $\mathrm{X}_{2}$ on $\theta_{\mathrm{s}, \mathrm{X} 1}, \alpha_{\mathrm{s}, \mathrm{X} 1}, \theta_{\mathrm{s}, \mathrm{X} 1}$, and $\gamma_{\mathrm{X} 1}$ at high $\left[\mathrm{X}_{1}\right]_{\mathrm{gs}}$ clearly distinguishes SS4 from the other models systems.

The characteristic differences between SS4 and the other models systems should enable the distinction of surface layer and gas-surface reactions (Langmuir-Hinshelwood and EleyRideal mechanisms) in experimental investigations, provided that the range of basic rate parameters and experimental conditions are appropriate. In practice, however, the distinction may not always be straightforward and time dependencies may need to be considered as outlined in Sect. 2 .

3.5 Model system Steady-State 5 (SS5): solubility-driven gas uptake

In model system SS5, a trace gas $\mathrm{X}_{1}$ undergoes reversible adsorption and surface-bulk transport (solvation and desolvation) onto and into a liquid droplet, but no chemical reactions. Under quasi-steady-state conditions this system can be described by the following equations derived from the general PRA adsorption-reaction steady-state equations (PRA Sect. 4.5.1, Special Case B):

$$
\begin{aligned}
& K_{\mathrm{ads}, \mathrm{X} 1}^{\prime}=\alpha_{\mathrm{s}, 0, \mathrm{X} 1} \frac{\sigma_{\mathrm{X} 1} \omega_{\mathrm{X} 1}}{4\left(k_{\mathrm{d}, \mathrm{X} 1}+k_{\mathrm{s}, \mathrm{b}, \mathrm{net}, \mathrm{X} 1}\right)} \\
& \theta_{s}=\frac{K_{\mathrm{ads}, \mathrm{X} 1}^{\prime}\left[\mathrm{X}_{1}\right]_{\mathrm{gs}}}{1+K_{\mathrm{ads}, \mathrm{X} 1}^{\prime}\left[\mathrm{X}_{1}\right]_{\mathrm{gs}}} \\
& \alpha_{\mathrm{s}, \mathrm{X} 1}=\frac{\alpha_{\mathrm{s}, 0, \mathrm{X} 1}}{1+K_{\mathrm{ads}, \mathrm{X} 1}^{\prime}\left[\mathrm{X}_{1}\right]_{\mathrm{gs}}} \\
& \alpha_{\mathrm{b}, \mathrm{X} 1}=\alpha_{\mathrm{s}, \mathrm{X} 1} \frac{k_{\mathrm{s}, \mathrm{b}, \mathrm{X} 1}}{k_{\mathrm{s}, \mathrm{b}, \mathrm{X} 1}+k_{\mathrm{d}, \mathrm{X} 1}}
\end{aligned}
$$

For the exemplary model simulations based on Eqs. (45)(48) and illustrated in Fig. 14, the basic input parameters were the same as in model systems L1 and L2: $\alpha_{\mathrm{s}, 0, \mathrm{X} 1}=1 ; \omega_{\mathrm{X} 1}=3.1 \times 10^{4} \mathrm{~cm} \mathrm{~s}^{-1} ; \tau_{\mathrm{d}, \mathrm{X} 1}=1.7 \times 10^{-5} \mathrm{~s}$ and $k_{\mathrm{d}, \mathrm{X} 1}=5.8 \times 10^{4} \mathrm{~s}^{-1}, \sigma_{\mathrm{X} 1}=1.0 \times 10^{-14} \mathrm{~cm}^{2} . k_{\mathrm{b}, \mathrm{s}, \mathrm{X} 1}$ was set to $32.3 \mathrm{~cm} \mathrm{~s}^{-1}$, and in scenarios SS5-1 to SS5-7 (Table 3) $k_{\mathrm{s}, \mathrm{b}, \mathrm{X} 1}$ was varied to match different Henry's law coefficients (Eq. 23, Sect. 2.2.1) ranging from $H_{\mathrm{cp}, \mathrm{X} 1}=0.1 \mathrm{M} / \mathrm{atm}$ and $k_{\mathrm{s}, \mathrm{b}}=5.8 \times 10^{2} \mathrm{~s}^{-1}$ (scenario SS5-1) to $H_{\mathrm{cp}, \mathrm{X} 1}=10^{5} \mathrm{M} / \mathrm{atm}$ and $k_{\mathrm{s}, \mathrm{b}}=5.8 \times 10^{8} \mathrm{~s}^{-1}$ (scenario SS5-7). The parameters for SS5-2 are closest to those of scenarios L1-1 to L1-3 and L2-1 to L2-3, respectively.

In scenarios SS5-1 to SS5-7 we build on model system L2 (large droplets and limitation of gas uptake by liquid phase diffusion) and assume quasi-steady state conditions
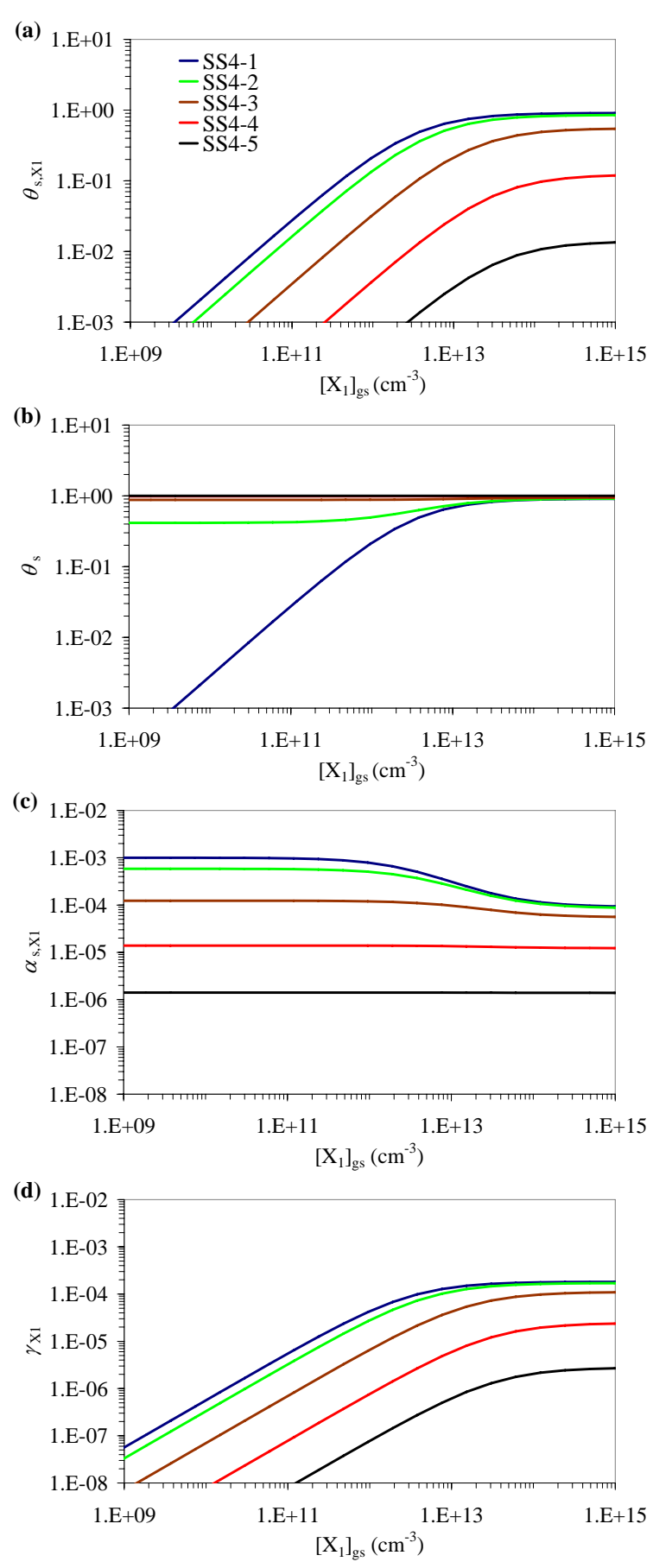

Fig. 13. Exemplary numerical simulations for model system Steady-State 4 (SS4), describing competitive co-adsorption of trace gases $\mathrm{X}_{1}$ and $\mathrm{X}_{2}$, and gas-surface self-reaction of $\mathrm{X}_{1}$ : fractional surface coverage $\theta_{\mathbf{S}, \mathrm{X} 1}(\mathbf{a})$, total sorption layer surface coverage $\theta_{\mathbf{S}}$ (b), surface accommodation coefficient $\alpha_{\mathrm{s}, \mathrm{X} 1}$ (c), and uptake coefficient $\gamma_{\mathrm{X} 1}$ (d) as a function of near-surface gas phase concentration $\left[\mathrm{X}_{1}\right]_{\mathrm{gs}}$ for scenarios SS4-1 ([X $]_{\mathrm{gs}}=0$, blue, identical with SS1-1 in Fig. 10 and Table 2), SS4-2 ([X $]_{\mathrm{gs}}=2.5 \times 10^{12} \mathrm{~cm}^{-3}$, green $), \mathrm{SS} 4-3$ $\left(\left[\mathrm{X}_{2}\right]_{\mathrm{gs}}=2.5 \times 10^{13} \mathrm{~cm}^{-3}\right.$ yellow $), \mathrm{SS} 4-4\left(\left[\mathrm{X}_{2}\right]_{\mathrm{gs}}=2.5 \times 10^{14} \mathrm{~cm}^{-3}\right.$, red), and SS4-5 $\left(\left[\mathrm{X}_{2}\right]_{\mathrm{gs}}=2.5 \times 10^{15} \mathrm{~cm}^{-3}\right.$, black $)$. 
Table 3. Scenarios, rate parameters, adsorption equilibrium constant and solubility for model system SS5 describing adsorption and surfacebulk transport into a liquid droplet under quasi-steady-state conditions. See Tables 1 and 2 for explanation of symbols.

\begin{tabular}{llllll}
\hline Scenario & $\begin{array}{l}k_{\mathrm{s}, \mathrm{b}, \mathrm{X} 1} \\
\left(\mathrm{~s}^{-1}\right)\end{array}$ & $\begin{array}{l}k_{\mathrm{s}, \mathrm{b}, \mathrm{net}, \mathrm{X} 1} \\
\left(\mathrm{~s}^{-1}\right)\end{array}$ & $\begin{array}{l}K_{\mathrm{ads}, \mathrm{X} 1}^{\prime} \\
\left(\mathrm{cm}^{3}\right)\end{array}$ & $\begin{array}{l}H_{\mathrm{cc}, \mathrm{X} 1} \\
(-)\end{array}$ & $\begin{array}{l}H_{\mathrm{cp}, \mathrm{X} 1} \\
\left(\mathrm{~mol} \mathrm{~L}^{-1} \mathrm{~atm}^{-1}\right)\end{array}$ \\
\hline SS5-1 & 584 & 0.89 & $1.35 \times 10^{-15}$ & 2.45 & 0.1 \\
SS5-2 & $5.84 \times 10^{3}$ & 8.91 & $1.35 \times 10^{-15}$ & $2.45 \times 10^{1}$ & 1 \\
SS5-3 & $5.84 \times 10^{4} \approx k_{\mathrm{d}}$ & 89.1 & $1.35 \times 10^{-15}$ & $2.45 \times 10^{2}$ & 10 \\
SS5-4 & $5.84 \times 10^{5}$ & $8.91 \times 10^{2}$ & $1.33 \times 10^{-15}$ & $2.45 \times 10^{3}$ & $10^{2}$ \\
SS5-5 & $5.84 \times 10^{6}$ & $8.91 \times 10^{3}$ & $1.17 \times 10^{-15}$ & $2.45 \times 10^{4}$ & $10^{3}$ \\
SS5-6 & $5.84 \times 10^{7}$ & $8.91 \times 10^{4} \approx k_{\mathrm{d}}$ & $5.33 \times 10^{-16}$ & $2.45 \times 10^{5}$ & $10^{4}$ \\
SS5-7 & $5.84 \times 10^{8}$ & $8.91 \times 10^{5}$ & $8.27 \times 10^{-17}$ & $2.45 \times 10^{6}$ & $10^{5}$ \\
\hline
\end{tabular}

which can be described by Eqs. (24) and (25). The liquid phase diffusion coefficient was set to $7.65 \times 10^{-6} \mathrm{~cm}^{2} \mathrm{~s}^{-1}$, and $k_{\mathrm{s}, \mathrm{b}, \text { net, } \mathrm{X} 1}$ was calculated using Eq. (25) with $\mathrm{t}=10^{-3} \mathrm{~s}$, i.e. for a time, where (quasi-)steady-state concentrations of $\mathrm{X} 1$ have been established at the surface and in the near surface bulk and where further gas uptake is determined by the dissolvo-diffusive flux towards the particle core (Sect. 2.2.2).

Figure $14 \mathrm{a}-\mathrm{d}$ displays $\theta_{\mathrm{s}}, \alpha_{\mathrm{s}, \mathrm{X} 1}, \alpha_{\mathrm{b}, \mathrm{X} 1}$, and $\gamma_{\mathrm{X} 1}$ as a function of gas phase concentration for the five scenarios SS51 to SS5-7 with different (net) surface-to-bulk mass transport rate coefficients and effective adsorption equilibrium constants (Table 3 ). In all scenarios $\theta_{\mathrm{s}, \mathrm{X} 1}$ increases nearlinearly with $\left[\mathrm{X}_{1}\right]_{\mathrm{gs}}$, while $\alpha_{\mathrm{s}, \mathrm{X} 1}, \alpha_{\mathrm{b}, \mathrm{X} 1}$, and $\gamma_{\mathrm{X} 1}$ are independent of $\left[\mathrm{X}_{1}\right]_{\mathrm{gs}}$ as long as $\left[\mathrm{X}_{1}\right]_{\mathrm{gs}} \ll 1 / K_{\text {ads, } \mathrm{X} 1}^{\prime}\left(\theta_{\mathrm{s}, \mathrm{X} 1} \ll 1\right)$. At $\left[\mathrm{X}_{1}\right]_{\mathrm{gs}} \approx 1 / K_{\mathrm{ads}, \mathrm{X} 1}^{\prime}$ the effects of reversible and competitive adsorption inhibit the increase of $\theta_{\mathrm{s}}$ with $\left[\mathrm{X}_{1}\right]_{\mathrm{gs}}$, and induce a decrease of $\alpha_{\mathrm{s}, \mathrm{X} 1}, \alpha_{\mathrm{b}, \mathrm{X} 1}$, and $\gamma_{\mathrm{X} 1}$ with $\left[\mathrm{X}_{1}\right]_{\mathrm{gs}}$ (surface saturation with $\theta_{\mathrm{s}}$ approaching unity).

The decrease of accommodation and uptake coefficients due to surface saturation effects at high gas phase concentrations is consistent with the observations reported by Jayne et al. (1990) for the uptake of $\mathrm{SO}_{2}$ into acidic aqueous solution droplets. As discussed in the preceding companion paper (PRA Sect. 3.5.2), such surface saturation effects are expected to be particularly important for gas uptake and partitioning in case of high concentrations (laboratory studies) and viscous liquids with slow surface-bulk mass transport (e.g. liquid organic droplets or particle coatings). They may, however, also be important for cloud droplets covered by organic surfactants, which might strongly influence the desorption and surface-to-bulk transfer rate coefficients. Such effects and their implications have recently been discussed by Djikaev and Tabazadeh (2003).

Between the different scenarios SS5-1 to SS5-7, the mass accommodation coefficients $\alpha_{\mathrm{b}, \mathrm{X} 1}$ exhibit a near-linear increase with $k_{\mathrm{s}, \mathrm{b}, \mathrm{X} 1}$ for $k_{\mathrm{s}, \mathrm{b}, \mathrm{X} 1} \ll k_{\mathrm{d}, \mathrm{X} 1}$ (scenarios SS5-1 to SS5-3) and approach the value of the surface accommodation coefficient $\alpha_{\mathrm{s}, \mathrm{X} 1}$ for $k_{\mathrm{s}, \mathrm{b}, \mathrm{X} 1}>k_{\mathrm{d}, \mathrm{X} 1}$ (scenarios SS5-5 to SS57; Fig. 14c). Similarly, the uptake coefficients $\gamma_{\mathrm{X} 1}$ exhibit a near-linear increase with $k_{\mathrm{s}, \mathrm{b}, \text { net, } \mathrm{X} 1}$ for $k_{\mathrm{s}, \mathrm{b}, \text { net, } \mathrm{X} 1} \ll k_{\mathrm{d}, \mathrm{X} 1}$ (scenarios SS5-1 to SS5-5) and approach the value of the surface accommodation coefficient $\alpha_{\mathrm{s}, \mathrm{X} 1}$ for $k_{\mathrm{s}, \mathrm{b}, \text { net, } \mathrm{X} 1}>k_{\mathrm{d}, \mathrm{X} 1}$ (scenarios SS5-6 and SS5-7; Fig. 14d). These simulations illustrate the close relation of adsorption and surface-bulk transfer rate coefficients with gas uptake and solubility in liquid particles.

3.6 Model system Steady-State 6 (SS6): solubility saturation

Model system SS6 describes the non-reactive partitioning of a volatile species $\mathrm{X}_{1}$ between the gas-phase and particle bulk at equilibrium (solubility saturation). It corresponds to model systems L1, L2, and SS5 at infinitely long gas-particle interaction time $\left(\mathrm{t}=\infty, J_{\mathrm{s}, \mathrm{b}, \text { net, } \mathrm{X} 1}=0\right)$. Under these conditions, the ratio between particle bulk and gas phase concentration of $X_{1}$ is determined by the equilibrium partitioning coefficient or solubility $K_{\mathrm{sol}, \mathrm{cc}, \mathrm{X} 1}$ as defined in Eq. (23) and PRA Sect. 3.5.2.

The exemplary simulations illustrated in Fig. 15 correspond to the scenarios of model systems L1, L2, and $\mathrm{SS} 5$, respectively, with $\alpha_{\mathrm{S}, 0, \mathrm{X} 1}=1 ; \omega_{\mathrm{X} 1}=3.1 \times 10^{4} \mathrm{~cm} \mathrm{~s}^{-1}$; $\sigma_{\mathrm{X} 1}=1 \times 10^{-14} \mathrm{~cm}^{2}$. For the variation of $\tau_{\mathrm{d}, \mathrm{X} 1}, k_{\mathrm{s}, \mathrm{b}, \mathrm{X} 1}$, $k_{\mathrm{b}, \mathrm{s}, \mathrm{X} 1}, K_{\mathrm{ads}, \mathrm{X} 1}^{\prime}, H_{\mathrm{cc}, \mathrm{X} 1}$, and $H_{\mathrm{cp}, \mathrm{X} 1}$ see Tables 1 and 3, respectively.

Figure 15 displays the equilibrium solubilities of $X_{1}$ in concentration and pressure units, $K_{\mathrm{sol}, \mathrm{cp}, \mathrm{X} 1}$, as a function of gas phase concentration for the three rate parameter combinations and Henry's law coefficients corresponding to the scenarios L1-1/L2-1 to L1-9/L2-9 (Fig. 15a) and for the seven combinations corresponding to scenarios SS5-1 to SS5-7 (Fig. 15b).

For all scenarios, $K_{\mathrm{sol}, \mathrm{cp}, \mathrm{X} 1}$ equals $H_{\mathrm{cp}, \mathrm{X} 1}$ as long as $\left[\mathrm{X}_{1}\right]_{\mathrm{gs}} \ll 1 / K_{\text {ads }, \mathrm{X} 1}^{\prime} \quad\left(\theta_{\mathrm{s}, \mathrm{X} 1} \ll 1, \quad \alpha_{\mathrm{s}, \mathrm{X} 1}=\alpha_{\mathrm{s}, 0, \mathrm{X} 1}\right)$. At $\left[\mathrm{X}_{1}\right]_{\mathrm{gs}} \approx 1 / K_{\mathrm{ads}, \mathrm{X} 1}^{\prime}$ the effects of reversible and competitive adsorption inhibit further increase of $J_{\mathrm{ads}, \mathrm{X} 1}, J_{\mathrm{s}, \mathrm{b}, \mathrm{X} 1}$ and $\left[\mathrm{X}_{1}\right]_{\mathrm{b} \text {, sat }}$ with $\left[\mathrm{X}_{1}\right]_{\mathrm{gs}}=\left[\mathrm{X}_{1}\right]_{\mathrm{g} \text {,sat }}$, inducing a decrease of $\alpha_{\mathrm{s}, \mathrm{X} 1}$ and $K_{\mathrm{sol}, \mathrm{cp}, \mathrm{X} 1}$ according to Eqs. (47) and (23). At 

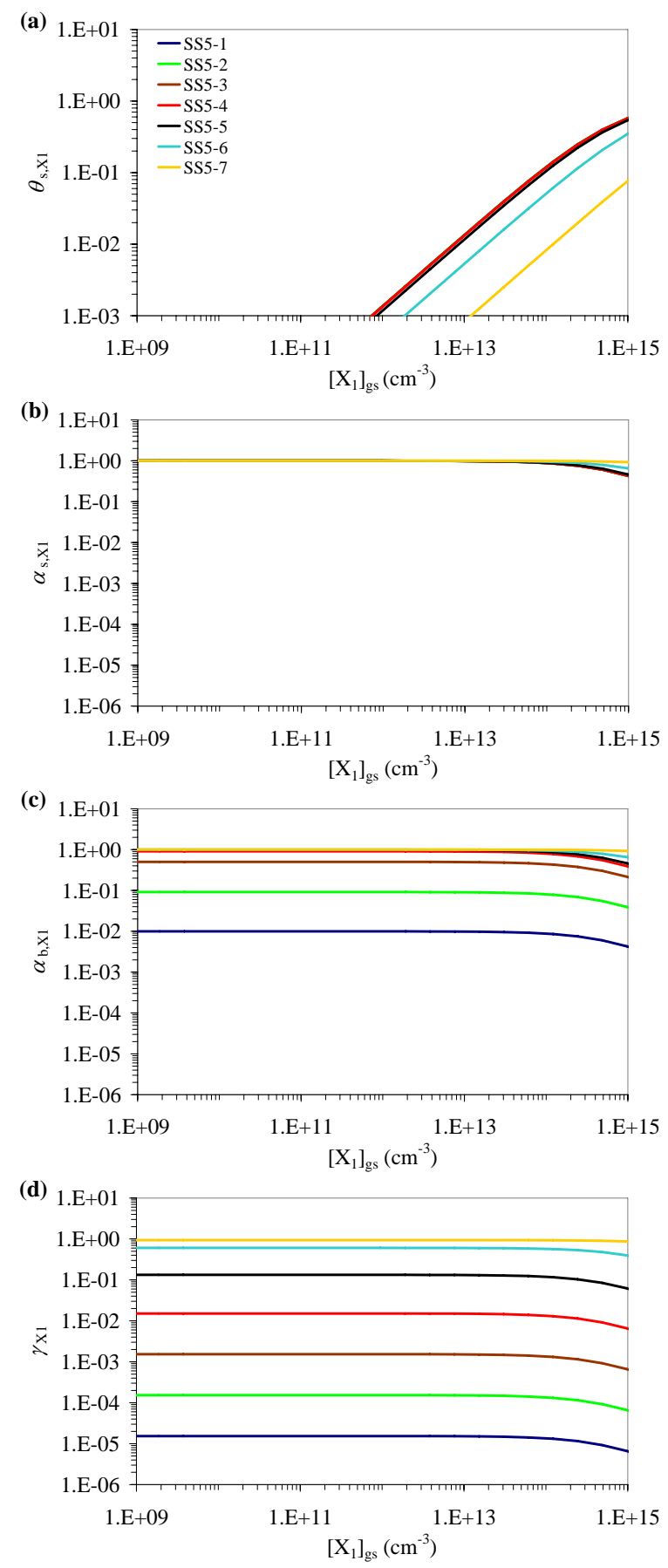

Fig. 14. Exemplary numerical simulations for model system Steady-State 5 (SS5), describing adsorption, and diffusion limited surface-bulk transport of a trace gas $\mathrm{X}_{1}$ (non-reactive solvation of a trace gas into a liquid): surface coverage $\theta_{\mathrm{s}, \mathrm{X} 1}(\mathbf{a})$, surface accommodation coefficient $\alpha_{\mathrm{s}, \mathrm{X} 1}$ (b), bulk accommodation coefficient, $\alpha_{\mathrm{b}, \mathrm{X} 1}$ (c) and uptake coefficient $\gamma_{\mathrm{X} 1}$ (d) as a function of near-surface gas phase concentration $\left[\mathrm{X}_{1}\right]_{\mathrm{gs}}$ for scenarios SS5-1 to SS5-7. The parameters for these scenarios (see Table 3) are representative of species with solubility ranging from 0.1 to $10^{5} \mathrm{M} / \mathrm{atm}$, respectively.
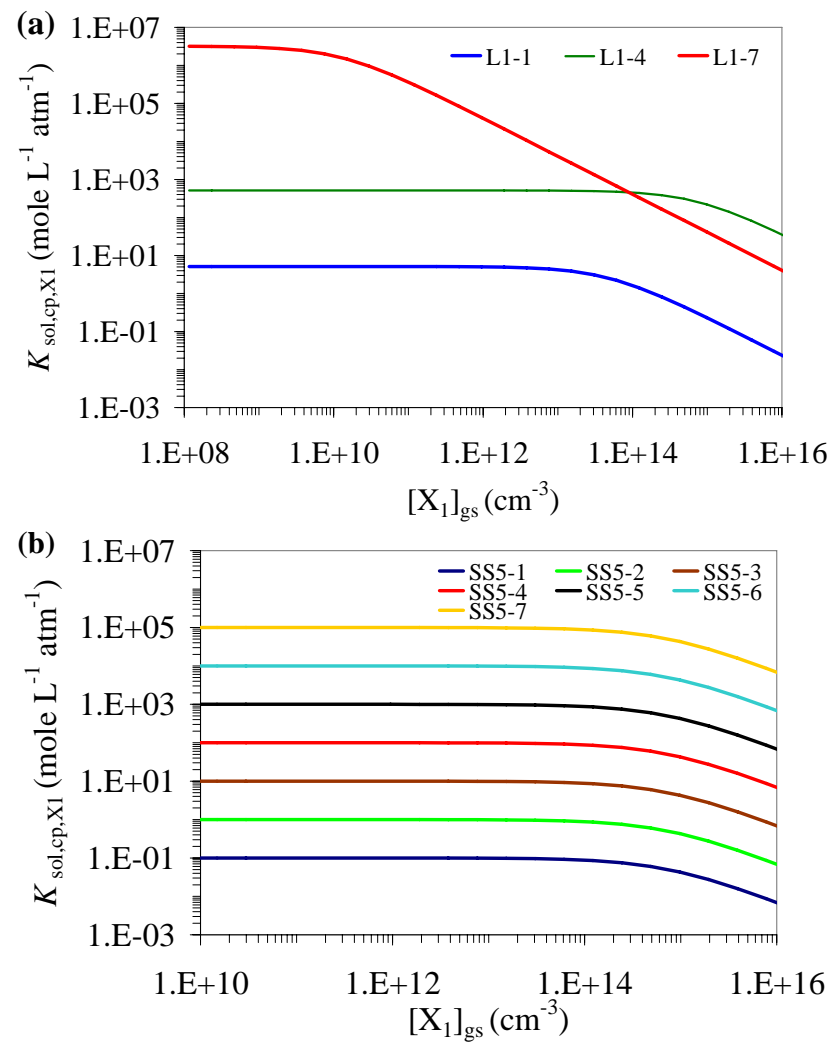

Fig. 15. Exemplary numerical calculations for model system Steady-State 6 (SS6), describing equilibrium of a trace gas $X_{1}$ undergoing adsorption and surface-bulk transport (non-reactive solvation of a trace gas into a liquid) between the bulk and the gas phases: solubility $K_{\text {sol,cp,X1 }}$, as a function of near-surface gas phase concentration $\left[\mathrm{X}_{1}\right]_{\mathrm{gs}}$ for the parameters defined in model system L1 (a, see Table 1) and model system SS5 (b, see Table 3).

$\left[\mathrm{X}_{1}\right]_{\mathrm{gs}} \gg 1 / K_{\mathrm{ads}, \mathrm{X} 1}^{\prime}$, the sorption layer surface coverage approaches unity, leading to a further decrease of $\alpha_{\mathrm{s}, \mathrm{X} 1}$ and $K_{\text {sol,cp,X1 }}$. Note that the concentration dependence of the solubility following from the kinetic model of gas-particle partitioning is consistent with the correction of thermodynamic Henry's law coefficients (limiting case for dilute solutions) by activity coefficients for concentrated solutions.

Figure 15 indicates that surface saturation effects on bulk solubility are not significant for most of the investigated scenarios at typical atmospheric trace gas concentration levels, but can be important for laboratory measurements of Henry's law coefficients at elevated concentrations (Shuntirasingham et al., 2007). For gas molecules with high affinity to the surface (long desorption lifetimes) and highly viscous liquid or solid particles with slow surface-bulk mass transport, however, surface saturation effects are likely to influence the solubility saturation equilibrium of the particle bulk even at atmospheric concentration levels (e.g. liquid organic droplets, coatings, or surfactant layers; Djikaev and Tabazadeh, 2003). 


\section{Summary and conclusions}

The model systems and scenarios presented in this paper demonstrate that the PRA framework can be used for efficient, flexible, and consistent description of surface chemistry and gas-particle interactions in aerosols and clouds. They illustrate how the general PRA mass balance and rate equations can be easily reduced to compact sets of equations, which enable a mechanistic description of time and concentration dependencies of trace gas uptake and particle composition in systems with one or more chemical components and physicochemical processes.

The exemplary numerical simulations in Sect. 2 show the effects of reversible adsorption, surface-bulk transport, and chemical aging on the temporal evolution of trace gas uptake by solid particles and solubility saturation of liquid particles. They illustrate how the transformation of particles and the variation of trace gas accommodation and uptake coefficients by orders of magnitude over time scales of microseconds to days can be explained and predicted from the initial composition and basic kinetic parameters of model systems by iterative calculations using standard spreadsheet programs. Moreover, they show how apparently inconsistent experimental data sets obtained with different techniques and on different time scales can be efficiently linked and mechanistically explained by application of consistent model formalisms and terminologies within the PRA framework. The time scales considered here are also covered by laboratory experiments, ranging from milliseconds in flow reactors to days in large atmospheric simulation chambers.

The simulations in Sect. 3 illustrate characteristic effects of gas phase composition and basic kinetic parameters on the rates of mass transport and chemical reactions under (quasi-)steady-state conditions. They demonstrate how adsorption and surface saturation effects can explain non-linear gas phase concentration dependencies of surface and bulk accommodation coefficients, uptake coefficients, and bulk solubilities (deviations from Henry's law). Such effects are expected to play an important role in many real atmospheric aerosol and cloud systems involving a wide range of organic and inorganic components of concentrated aqueous and organic solution droplets, ice crystals, and other crystalline or amorphous solid particles.

Both modeling approaches, the iterative solving of mass balance equations and the application of analytical equations describing (quasi-)steady-state conditions, can be applied for the analysis and interpretation of experimental data, for the design of experiments, for the establishment of comprehensive and self-consistent collections of basic rate parameters of aerosol and cloud processes, and for the flexible and consistent integration of specific processes and kinetic parameters into comprehensive aerosol, cloud, atmospheric, and climate models.

We hope that the presented model systems and simulations have clearly demonstrated the universal applicability and consistency of the PRA framework as a tool and common basis for experimental and theoretical studies investigating and describing atmospheric aerosol and cloud surface chemistry and gas-particle interactions.

Acknowledgements. The authors thank T. Bartels-Rausch, K. Carslaw, S. Clegg, T. Cox, N. Deisel, R. Garland, M. Kerbrat, D. Knopf, T. Mentel, N. Otto, T. Peter, R. Sander, Y. Rudich, U. Schurath, D. Worsnop, and many other members of the atmospheric science community for stimulating scientific discussions. This work was supported by the European Integrated Project on Aerosol Cloud Climate and Air Quality Interactions (EUCAARI). U. Pöschl acknowledges financial support by the German Federal Ministry of Education and Research (BMBF, AFO2000 07ATC05, CARBAERO). M. Ammann acknowledges financial support by the Swiss National Science Foundation (grant no 200020-100275).

Edited by: M. Kulmala

\section{References}

Ammann, M., Rössler, E., Baltensperger, U., and Kalberer M.: Heterogeneous reaction of $\mathrm{NO}_{2}$ on bulk soot samples, Laboratory of Radio- and Environmental Chemistry Annual Report 1997, 24, 1997.

Ammann, M., Kalberer, K., Jost, D. T., Tobler, L., Rössler, E., Piguet, D., Gäggeler, H. W., and Baltensperger, U.: Heterogeneous production of nitrous acid on soot in polluted air masses, Nature, 395, 157-160, 1998.

Ammann, M., Pöschl, U., and Rudich, Y.: Effects of reversible adsorption and Langmuir-Hinshelwood surface reactions on gas uptake by atmospheric particles, Phys. Chem. Chem. Phys., 5, 351-356, 2003.

Arens, F., Gutzwiller, L., Baltensperger, U., Gäggeler, H. W., and Ammann, M.: Heterogeneous reaction of $\mathrm{NO}_{2}$ on diesel soot particles, Environ. Sci. Technol., 35, 2191-2199, 2001.

Aubin, D. G. and Abbatt, J. P. D.: Interaction of $\mathrm{NO}_{2}$ with hydrocarbon soot: Focus on HONO yield, surface modification, and mechanism, J. Phys. Chem. A, 111, 6263-6273, 2007.

Lelièvre, S., Bedjanian, Y., Laverdet, G., and Le Bras, G.: Heterogeneous reaction of $\mathrm{NO}_{2}$ with hydrocarbon flame soot, J. Phys. Chem. A, 108, 10 807-10 817, 2004.

Djikaev, Y. S. and Tabazadeh, A.: Effect of adsorption on the uptake of organic trace gas by cloud droplets, J. Geophys. Res.-A, 108, 4689, doi:10.1029/2003JD003741, 2003.

Fendel, W. and Schmidt-Ott, A.: Ozone depletion potential of carbon aerosol particles, J. Aerosol Sci., 24, S317-S318, 1993.

Fendel, W., Matter, U., Burtscher, H., and Schmidt-Ott, A.: Interaction between carbon or iron aerosol particles and ozone, Atmos. Environ., 29, 967-973, 1995.

Finlayson-Pitts, B. J. and Pitts Jr., J. N.: Chemistry of the upper and lower atmosphere, Academic Press, San Diego, 159-164, 2000.

Gerecke, A., Thielmann, A., Gutzwiller, L., and Rossi, M. J.: The chemical kinetics of HONO formation resulting from heterogeneous interaction of $\mathrm{NO}_{2}$ with flame soot, Geophys. Res. Lett., 25, 2453-2456, 1998.

Huthwelker, T., Ammann, M., and Peter, T.: The uptake of acidic gases on ice, Chem. Rev., 106, 1375-1444, 2006. 
Hanson, D. R.: Reactivity of $\mathrm{ClONO}_{2}$ on $\mathrm{H}_{2}^{18} \mathrm{O}$ ice and organic liquids, J. Phys. Chem., 99, 13 059-13 061, 1995.

Jayne, J. T., Davidovits, P., Worsnop, D. R., Zahniser, M. S., and Kolb, C. E.: Uptake of $\mathrm{SO}_{2}(\mathrm{~g})$ by Aqueous Surfaces as a Function of $\mathrm{pH}$ - the Effect of Chemical-Reaction at the Interface, J. Phys. Chem., 94, 6041-6048, 1990.

Kamm, S., Mohler, O., Naumann, K. H., Saathoff, H., and Schurath, U.: The heterogeneous reaction of ozone with soot aerosol, Atmos. Environ., 33, 4651-4661, 1999.

Letzel, T., Pöschl, U., Rosenberg, E., Grasserbauer, M., and Niessner, R.: In-source fragmentation of partially oxidized mono- and polycyclic aromatic hydrocarbons in atmospheric pressure chemical ionization mass spectrometry coupled to liquid chromatography, Rapid Commun. Mass Spectrom., 13, 2456-2468, 1999.

Letzel, T., Pöschl, U., Wissiack, R., Rosenberg, E., Grasserbauer, M., and Niessner, R.: Phenyl-modified reversed-phase liquid chromatography coupled to atmospheric pressure chemical ionization mass spectrometry: A universal method for the analysis of partially oxidized aromatic hydrocarbons, Anal. Chem., 73, 1634-1645, 2001.

Letzel, T., Rosenberg, E., Wissiack, R., Grasserbauer, M., and Niessner, R.: Separation and identification of polar degradation products of benzo[a]pyrene with ozone by atmospheric pressure chemical ionization-mass spectrometry after optimized column chromatographic clean-up, J. Chromatogr. A, 855, 501-514, 1999.

Longfellow, C. A., Ravishankara, A. R., and Hanson, D. R.: Reactive and nonreactive uptake on hydrocarbon soot: $\mathrm{HNO}_{3}, \mathrm{O}_{3}$, and $\mathrm{N}_{2} \mathrm{O}_{5}$, J. Geophys. Res.-A, 105, 24 345-24 350, 2000.

Pöschl, U., Rudich, Y., and Ammann, M.: Kinetic model framework for aerosol and cloud surface chemistry and gas-particle interactions - Part 1: General equations, parameters, and terminology, Atmos. Chem. Phys., 7, 5989-6023, 2007, http://www.atmos-chem-phys.net/7/5989/2007/.
Pöschl, U., Letzel, T., Schauer, C., and Niessner, R.: Interaction of ozone and water vapor with spark discharge soot aerosol particles coated with benzo[a]pyrene: $\mathrm{O}_{3}$ and $\mathrm{H}_{2} \mathrm{O}$ adsorption, benzo[a]pyrene degradation and atmospheric implications, J. Phys. Chem. A, 105, 4029-4041, 2001.

Pöschl, U.: Formation and decomposition of hazardous chemical components contained in atmospheric aerosol particles, J. Aerosol Med., 15, 203-212, 2002.

Rogaski, C. A., Golden, D. M., and Williams, L. R.: Reactive uptake and hydration experiments on amorphous carbon treated with $\mathrm{NO} 2$, SO2, O3, HNO3, and $\mathrm{H} 2 \mathrm{SO} 4$, Geophys. Res. Lett., 24, 381-384, 1997.

Schauer, C., Niessner, R., and Pöschl, U.: Analysis of nitrated polycyclic aromatic hydrocarbons by liquid chromatography with fluorescence and mass spectrometry detection: air particulate matter, soot, and reaction product studies, Anal. Bioanal. Chem., 378, 725-736, 2004.

Smith, G. D., Woods, E., Baer, T., and Miller, R. E.: Aerosol uptake described by numerical solution of the diffusion - Reaction equations in the particle, J. Phys. Chem. A, 107, 9582-9587, 2003.

Shunthirasingham, C., Lei, Y. D., and Wania, F.: Evidence of bias in air-water henry's law constants for semivolatile organic compounds measured by inert gas stripping, Environ. Sci. Technol., 41, 3807-3814, 2007.

Stephens, S., Rossi, M., and Golden, D. M.: the heterogeneous reaction of ozone on carbonaceous surfaces, Int. J. Chem. Kinet., 18, 1133-1149, 1986.

Worsnop, D. R., Morris, J. W., Shi, Q., Davidovits, P., and Kolb, C. E.: A chemical kinetic model for reactive transformations of aerosol particles, Geophys. Res. Lett., 29, 1996, doi:10.1029/2002GL015542, 2002. 